\title{
Artemisia dracunculus (Tarragon): A Review of Its Traditional Uses, Phytochemistry and Pharmacology
}

\author{
Halina Ekiert ${ }^{1 *}$, Joanna Świątkowska ${ }^{1}$, Ewa Knut ${ }^{1}$, Paweł Klin ${ }^{2}$, Agnieszka Rzepiela ${ }^{3}$, \\ Michał Tomczyk ${ }^{4}$ and Agnieszka Szopa ${ }^{1 *}$
}

${ }^{1}$ Chair and Department of Pharmaceutical Botany, Jagiellonian University, Medical College, Kraków, Poland, ${ }^{2}$ Family Medicine Clinic, Medizinisches Versorgungszentrum (MVZ) Burgbernheim GmbH, Burgbernheim, Germany, ${ }^{3}$ Museum of Pharmacy, Jagiellonian University, Medical College, Kraków, Poland, ${ }^{4}$ Department of Pharmacognosy, Faculty of Pharmacy, Medical University of Białystok, Białystok, Poland

\section{OPEN ACCESS}

Edited by:

Andrei Mocan

Iuliu Haţieganu University of Medicine and Pharmacy, Romania

Reviewed by:

Claudio Ferrante,

University of Studies G. d'Annunzio

Chieti and Pescara, Italy Antoine Saab,

Lebanese University, Lebanon Adriana Trifan,

Grigore T. Popa University of Medicine and Pharmacy, Romania

${ }^{*}$ Correspondence: Halina Ekiert

halina.ekiert@uj.edu.p Agnieszka Szopa a.szopa@uj.edu.pl

Specialty section: This article was submitted to

Ethnopharmacology,

a section of the journal

Frontiers in Pharmacology

Received: 15 January 2021 Accepted: 01 March 2021

Published: 13 April 2021

Citation:

Ekiert H, Świątkowska J, Knut E, Klin P, Rzepiela A, Tomczyk M and Szopa A

(2021) Artemisia dracunculus

(Tarragon): A Review of Its Traditional

Uses, Phytochemistry

and Pharmacology.

Front. Pharmacol. 12:653993.

doi: 10.3389/fphar.2021.653993
Artemisia dracunculus L. (tarragon), Asteraceae, is a species that has long been used in traditional Asian medicine, mainly in Iran, Pakistan, Azerbaijan and India. It is known as a spice species in Asia, Europe and the Americas. The raw materials obtained from this species are herb and leaf. The presence of essential oil with a highly variable composition, as well as flavonoids, phenolic acids, coumarins and alkamides, determines the medicinal and/or spice properties of the plant. In traditional Asian medicine, this species is used, for example, in the treatment of digestive system diseases, as an analgesic, hypnotic, antiepileptic, anti-inflammatory and antipyretic agent, and as an effective remedy in the treatment of helminthiasis. Nowadays, $A$. dracunculus is the subject of professional phytochemical and pharmacological researches. Pharmacological studies have confirmed its anti-inflammatory and analgesic effects known from traditional uses; they have also proved very important new findings regarding its biological activity, such as antioxidant, immunomodulating and anti-tumour activities, as well as hepatoprotective and hypoglycaemic effects. A. dracunculus has long-held an established position in the food industry as a spice. And its use is growing in the cosmetics industry. Moreover, it is the subject of biotechnological research focused mainly on the development of micropropagation protocols.

Keywords: tarragon, traditional medicine use, chemical composition, biological activity, potential medicinal value, position in cosmetology, biotechnological studies

\section{INTRODUCTION}

Over the last few years, there has been a noticeable increase in interest in phytochemical and pharmacological studies concerning various species of the genus Artemisia L (Asteraceae) (Tan et al., 1998; Willcox, 2009; Koul and Taak, 2017). This interest is undoubtedly due to the fact that the Nobel Prize in Physiology or Medicine 2015 was awarded for the discovery in Artemisia annua (annual mugwort) of artemisinin-a sesquiterpenoid lactone, and proving its effectiveness in the treatment of malaria (Długońska, 2015; Efferth et al., 2015). Among the subjects of research is A. dracunculus, a species native to Siberia and Mongolia. In Europe, this species is a popular spice plant; in Asian countries (Iran, Pakistan, Azerbaijan, India), this species has long been used in traditional medicine. It has been used both in the treatment of gastrointestinal diseases and as an anesthetic, hypnotic and anti-epileptic agent. It has been 
recommended as an effective treatment for inflammation, fever and helminthiasis (Aglarova et al., 2008; Bora and Sharma, 2011; Obolskiy et al., 2011).

Contemporary professional research has proven various important aspects of the biological activity of extracts from both the entire aerial part and/or leaves of this species, as well as from its essential oil. Its antibacterial, antifungal and antiprotozoal properties have been documented, together with its extremely valuable antioxidant, immunomodulatory and antineoplastic properties (Abtahi Froushani et al., 2016; Hassanzadeh et al., 2016; Bedini et al., 2017; Navarro-Salcedo et al., 2017; Mohammadi et al., 2020). These studies have also been proven to have hepatoprotective, hypoglycaemic and thyroid regulating effects (Méndez-Del Villar et al., 2016; Zarezade et al., 2018; Mohammadi et al., 2020). An antidepressant effect has also been documented (Wang et al., 2018). The anti-inflammatory and analgesic effects known from applications in traditional medicine have also been confirmed (Abtahi Froushani et al., 2016; Wang et al., 2018; Safari et al., 2019). Moreover, an examination of relevant professional research also shows that the position of $A$. dracunculus as a plant species with cosmetic properties is rising (Ribnicky et al., 2004; Yamada et al., 2011; Chaleshtori et al., 2013). According to modern research, tarragon appears not only to maintain its position as a valuable spice plant, but above all, as an important plant with potential medicinal and cosmetic properties.

The main goal of this review is to present the latest research on both the chemistry and new findings on the biological activity of A. dracunculus, proven by professional research. Earlier reviews by Aglarova et al. and Obolskiy et al. (Aglarova et al., 2008; Obolskiy et al., 2011) are quite generalized and don't contain the latest, detailed information on this species, which is valuable in relation to pharmacology, cosmetology and food industries. In addition, the paper encompasses all previously known information concerning its biology and chemistry as well as the traditional medicine and culinary applications of the species under consideration.

\section{GENERAL INFORMATION ON THE SPECIES}

The name Artemisia dracunculus is derived from the Latin word "dracunculus" meaning "a small dragon", and refers to the shape of the leaves, which resemble dragon tongues (Aglarova et al., 2008). A. dracunculus has numerous (about 50) Latin synonyms, including Absinthium cernuum Moench, Achillea dracunculus Hort., Artemisia aromatica A. Nelson, A. cernua Nutt., A. crithmifolia L., A. dracunculiformis Krasch., A. dracunculina S. Wats., A. dracunculoides Pursh (GBIF.org (2020); The Plant List, 2013; Catalogue of Life, 2020; Missouri Botanical Garden, 2020). The English names include tarragon, estragon, dragon sagewort, dragon wormwood, false tarragon, French tarragon, green sagewort, linear-leaved wormwood, Russian tarragon, silky wormwood, tarragon sagewort. Some of the foreign names are Estragon (Ger.), dragon, estragon (Fr.), dragoncillo, estragão (Sp.), estragão (Port.), dragon, dragon, long hao (Chin.), pelyněk kozalec (Czech.), połyń estragon (Russ.), tárkony üröm (Hung.), and vaistinis kietis (Georg.) (GBIF.org (2020); The Plant List, 2013; Catalogue of Life, 2020; Missouri Botanical Garden, 2020). The raw materials are dried A. dracunculus aerial parts and leaves-Dracunculi herba and Dracunculi folium, with an intense, aromatic fragrance (Food and Drug Administration, 2020).

A. dracunculus is a hairless perennial, reaching a height of up to $150 \mathrm{~cm}$. Its straight stems are ribbed and have no flowers in the lower parts. The leaves are arranged alternately, sessile. The lower leaves are tripartite at the apex, while the middle and upper leaves are lanceolate. The tip of the leaf is sharp and the leaf blade margins entire. Yellow, tubular flowers are gathered in hanging, spherical capitula forming loose panicles. The fruit are achenes. The plant has strong, woody rhizomes, $0.5-1.5 \mathrm{~cm}$ thick, from which clusters of small roots grow (Aglarova et al., 2008; Bakova et al., 2017; Koul and Taak, 2017). A. dracunculus originates from areas of Siberia and Mongolia (Aglarova et al., 2008). In its natural habitats, this species can be found in Central Asia, in Mediterranean countries, in Eastern Europe and in North America. A. dracunculus grows in meadows in alkaline soils, in birch forests, near rivers, on mountain slopes and steppes (Aglarova et al., 2008).

A. dracunculus is a plant widely cultivated in the Americas, Asia and Europe. Two varieties are usually grown on plantations: French tarragon, otherwise known as true tarragon, and German tarragon (Artemisia dracunculus var. sativa). Russian tarragon is also found among the cultivated plants (miscellaneous varieties, including A. dracunculus var. dracunculoides, and A.dracunculus var. inodora). It is not popular, however, because of the poorer taste and less intense fragrance of the leaves (Eisenman et al., 2011; Obolskiy et al., 2011; Watson and Kennel, 2014).

A. dracunculus has low requirements in terms of cultivation site and care, but the highest yields are obtained from crops growing on moist, sandy-clay soils with an alkaline reaction. This species, depending on the cultivar, can be propagated vegetatively or from seed (Russian tarragon), or solely vegetatively from rhizome cuttings (French and German tarragon). It is also possible to use the in vitro micropropagation protocols developed for this species-described later in this review. In European conditions, plantations are established in april. The cuttings are placed in rows spaced at $60 \mathrm{~cm}$ and covered with a thin layer of soil. The first harvest of the herb takes place in dry weather in the same year, while in the following years two-tothree harvests can be gathered per year. The collected raw material is dried in drying sheds with natural air circulation or heated to $35^{\circ} \mathrm{C}$. After drying, the leafy parts of the tarragon plant are separated from the hard stems (Aglarova et al., 2008; Eisenman et al., 2011; Obolskiy et al., 2011; Watson and Kennel, 2014).

The main component of the raw materials, i.e. herb and leaves, is essential oil. The composition of $A$. dracunculus essential oil depends, inter alia, on the location of the cultivation site, the salinity of the soil and the age of the plant. The highest concentrations of the essential oil are observed at the beginning of leaf budding and at the beginning of flowering. The main components of the essential oil are: estragole, otherwise 


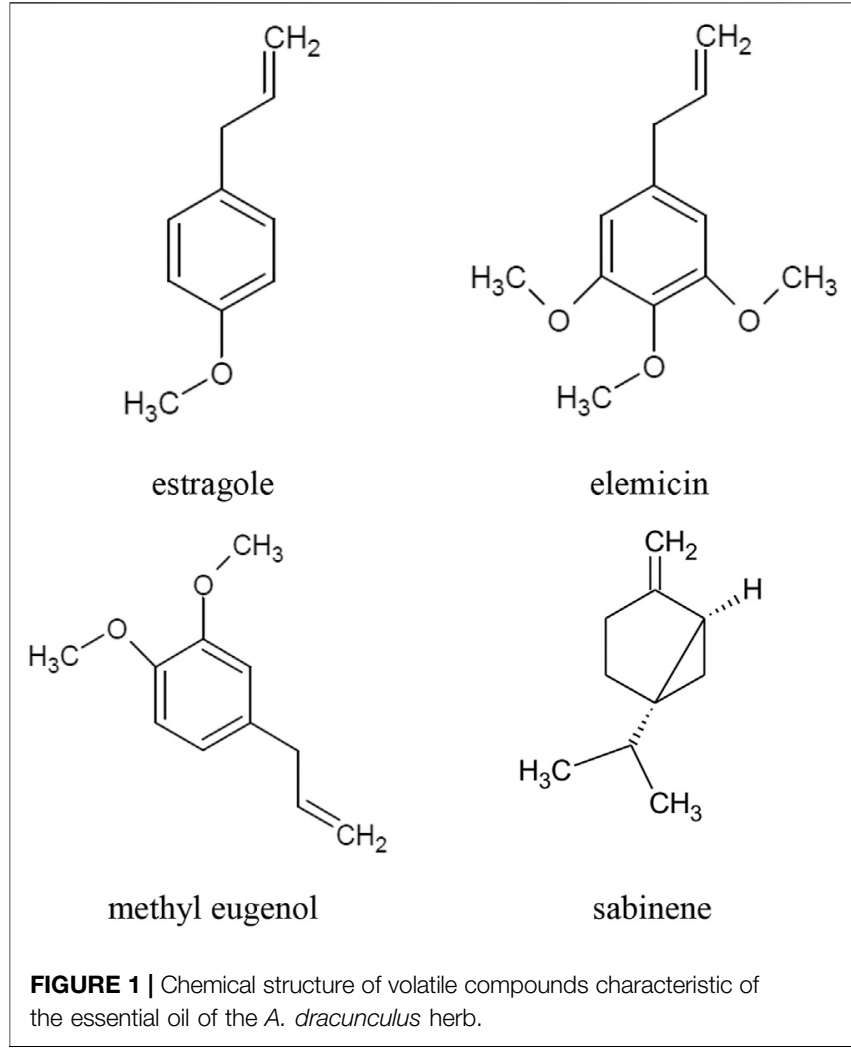

known as methyl chavicol or p-allylanisole (40-85\%), sabinene (approx. 35\%), methyl eugenol (approx. 25\%), and elemicin (up to $57 \%$ ) (Figure 1). Other compounds present in the oil in concentrations greater than $10 \%$ are: terpinen- 4 -ol, $\beta$-ocimene, cis-ocimene, $\alpha$-trans-ocimene, limonene and trans-anethole, $\alpha$-phellandrene, $\quad \beta$-phellandrene $(Z)$-artemidin, $\quad$ capillene (Table 1) (Aglarova et al., 2008; Ayoughi et al., 2011; Obolskiy et al., 2011; Tak et al., 2014; Karimi et al., 2015; Abdollahnejad et al., 2016; Hassanzadeh et al., 2016; Joshi et al., 2016; Bedini et al., 2017; Sharopov et al., 2020). Phenylpropanoids (73.5\%) constitute the main group of essential oil compounds. Monoterpenoids (24.3\%) and sesquiterpenoids $(0.2 \%)$ are present in the oil in considerably smaller amounts (Talbi et al., 2016; Bedini et al., 2017).

The tarragon plant contains numerous coumarins, mainly herniarin (Figure 2), as well as coumarin, scopoletin, scoparone, dracumerin, artemidine, esculetin, esculin, and capillarin. The total amount of coumarins in the herb is over $1.0 \%$. The biosynthesis of these compounds begins at an early stage of plant development; therefore, in three-month-old specimens, the coumarin content may even reach $1.3 \%$. The maximum level of this group of compounds has been found in five-year-old plants (Aglarova et al., 2008; Bhutia and Valant-vetschera, 2008; Obolskiy et al., 2011; Talbi et al., 2016; Mumivand et al., 2017; Bussmann et al., 2020; Sharopov et al., 2020).

A. dracunculus has also been found to contain flavonoids, the concentration of which in wild plants varies between 0.5 and $1.9 \%$. Under cultivation conditions, a maximum content of $4.9 \%$ can be obtained. Flavonoids typical of this species include quercetin, kaempferol, luteolin, isorhamnetin and their glycosides, naringenin, annagenin (5,6,7,8, $4^{\prime}$-pentahydroxy- $3^{\prime}$ methoxyflavone), pinocembrin and estragonoside C. A. dracunculus herb extracts have also been proven to contain phenolic acids, mainly chlorogenic acid, caffeic acid and vanillic acid. Other compounds found in the plant include alkamides (neopellitorine A, neopellitorine B, pellitorine), polyacetylenes, tannins, bitterness-imparting compounds, vitamin $\mathrm{C}$, fatty acids and sterols, iodine compounds, and peroxidase (Aglarova et al., 2008; Mumivand et al., 2017; Jahani et al., 2019; Bussmann et al., 2020).

The chemical composition of $A$. dracunculus and the compounds contained in the plant's essential oil are presented in Table 2.

\section{IMPORTANCE IN THE HISTORY OF MEDICINE AND PHARMACY}

According to Pliny the Elder (1st c. AD), the name A. dracunculus L., a diminutive of the Latin word "draco" - dragon (Gr. $\delta \rho \alpha \dot{\kappa} \omega \omega v)$, dracunculus-a small dragon, was given to this plant because of its serpentine rhizomes (Plinii Secundii, 1845). It was supposed to protect against snakebite when carried on one's body or imbibed as a drink, and its juice was used in ear diseases. The name $A$. dracunculus might also be a distorted version of the Arabic name for tarragon, i.e. tharchum, from which the synonyms tarchon, tarcon and torchun are derived (Rejewski, 1996).

The term "dracunculus" was often used by ancient authors, e.g. by Dioscorides (1st c. AD), to refer to another species-Arum dracunculus L. (Gr. Drakontaia megale, $\Delta$ paкоvтаía $\mu \varepsilon \gamma$ á $\lambda$ ), or

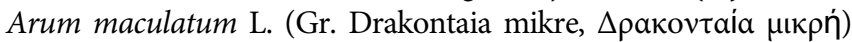
(Pedanius, 1998). A. dracunculus L. was commonly called draco, e.g. the botanist and German physician Valerius Cordus (16th c.) uses the name Draco sativus. Due to the similarity of dracunculus leaves to those of flax, it was believed to grow from flax seeds embedded in a hollowed-out onion (ex semine lini in cepe), meaning that it did not grow naturally. Authors such as K. Gessner (Bibliotheca Universalis 1545), P. Matthiolus (Commentarii in sex libros Pedacii Dioscoridis Anazarbi de Medicina material 1570) and J. Dalechamps (Historia Generalis Plantarum 1586) did not agree with this view (Bauhin and Cherler, 1651).

P. Matthiolus (1501-1577) describes tarragon (German version Dragoncell, Dracuncellus, Dragoncellus, Dracunculus esculentus) with the following: sharp taste, warming effect, stimulating the appetite (int.), externally applied with saliva, leaves crushed, mixed with honey, smeared causes bruises to disappear (Avicenna calls it "tarcon") (Mattioli, 1586).

In the 17th-century "Herbarium" by Simon Syrennivs (1613), A. dracunculus L. bears the Polish name "torchun", besides Dracunculus hortensis, Dragoncellus esculentus and also Draconkraut and Dragoncello. Its leaves are described as "elongated as flax leaves", and the taste as "very peppery" or "spicy". The plant has drying, warming and stimulating properties, relieves toothache, "removes mucus from the head", stimulates digestion and has a diuretic effect. Commonly, tarragon is used in place of lettuce or in salad 
TABLE 1 | Chemical composition of $A$. dracunculus essential oil.

Compounds

Phenylpropane derivatives

Estragole (methylchavicol, $p$-allylanisole)

Methyl eugenol

Elemicin

Isoelemycin

Eugenol

Isoeugenol methyl ether

Asarone, isoeugenol methyl trans-anethole

(Z)-Anethole

Prestragol

Anethole, carpacin

Dillapiole

3-(p-Methoxyphenyl)-1,2-propanediol

Monoterpenoids

Sabinene

cis allo-Ocymen, cis allo-ocymen hydrate, trans-sabinene acetate, ethyl geranyl $\alpha$-Fenchene, cis-sabinene hydrate, camphor, geranyl acetate, $(E)-\beta$-ionone

$\gamma$-Terpinene

$\alpha$-Terpinene

$\alpha$-Terpineol

4-Terpineol

Terpinolene

\section{$\alpha$-Terpinolene}

Linalool

Limonene

allo-Ocimene
trans-allo-Ocimene
cis- $\beta$-Ocimene
trans $\beta$-Ocimene
Citronellol
Citronellol acetate, neryl acetate
Citronellol formate, terpineol, $\alpha$-trans-ocimene, $\beta$-ocimene
(E)- $\beta$-o-cymene $p$-mentha-1,3,8-triene
o-Cymene
$\beta$-Ocimene Y, allocimene, geranial, nerol, $\beta$-elemene, tricyclen
4-Carene, $D$-limonene, 1,8-cineole, trans-4 thujanol
Carvone
Myrcene
Phellandrene
$\alpha$-Phellandrene
$\beta$-Phellandrene
$\alpha$-Thujene

\section{References}

Ayoughi et al. (2011), Obolskiy et al. (2011), Obistioiu et al. (2014), Tak et al. (2014), Karimi et al. (2015), Abdollahnejad et al. (2016), Abtahi Froushani et al. (2016), Behbahani et al. (2017), Osanloo et al. (2017), Bussmann et al. (2020), Sharopov et al. (2020)

Ayoughi et al. (2011), Obolskiy et al. (2011), Obistioiu et al. (2014), Tak et al. (2014), Karimi et al. (2015), Abdollahnejad et al. (2016), Abtahi Froushani et al. (2016),

Behbahani et al. (2017), Osanloo et al. (2017), Szczepanik et al. (2018), Bussmann et al. (2020), Sharopov et al. (2020)

Ayoughi et al. (2011), Obolskiy et al. (2011), Szczepanik et al. (2018), Bussmann et al. (2020)

Obolskiy et al. (2011), Szczepanik et al. (2018)

Ayoughi et al. (2011), Osanloo et al. (2017), Bussmann et al. (2020)

Szczepaniket al. (2018), Socaciu et al. (2020)

Obolskiy et al. (2011)

Ayoughi et al. (2011), Obolskiy et al. (2011), Bussmann et al. (2020)

Talbi et al. (2016)

Abdollahnejad et al. (2016)

Ayoughi et al. (2011), Behbahani et al. (2017)

Güvenalp et al. (2017)

Aglarova et al. (2008), Ayoughi et al. (2011), Obolskiy et al. (2011), Karimi et al. (2015), Bedini et al. (2017), Behbahani et al. (2017), Osanloo et al. (2017), Bussmann et al. (2020), Sharopov et al. (2020), Socaciu et al. (2020)

Obolskiy et al. (2011), Bussmann et al. (2020)

Sharopov et al. (2020)

Ayoughi et al. (2011), Obolskiy et al. (2011), Bedini et al. (2017), Osanloo et al. (2017), Szczepanik et al. (2018), Sharopov et al. (2020), Socaciu et al. (2020) Ayoughi et al. (2011), Obolskiy et al. (2011), Bedini et al. (2017), Osanloo et al. (2017), Szczepanik et al. (2018), Sharopov et al. (2020)

Aglarova et al. (2008), Bedini et al. (2017), Szczepanik et al. (2018)

Obolskiy et al. (2011), Szczepanik et al. (2018), Sharopov et al. (2020)

Aglarova et al. (2008), Ayoughi et al. (2011), Obolskiy et al. (2011), Karimi et al. (2015), Bedini et al. (2017), Szczepanik et al. (2018), Bussmann et al. (2020),

Sharopov et al. (2020), Socaciu et al. (2020)

Behbahani et al. (2017), Osanloo et al. (2017)

Ayoughi et al. (2011), Obolskiy et al. (2011), Bedini et al. (2017), Behbahani et al. (2017), Osanloo et al. (2017), Szczepanik et al. (2018), Sharopov et al. (2020) Aglarova et al. (2008), Ayoughi et al. (2011), Obolskiy et al. (2011), Karimi et al. (2015), Bedini et al. (2017), Behbahani et al. (2017), Osanloo et al. (2017), Szczepanik et al. (2018), Bussmann et al. (2020), Sharopov et al. (2020) Ayoughi et al. (2011), Obolskiy et al. (2011), Bedini et al. (2017), Behbahani et al. (2017)

Bussmann et al. (2020), Sharopov et al. (2020)

Joshi et al. (2016), Sharopov et al. (2020), Socaciu et al. (2020)

Aglarova et al. (2008), Sharopov et al. (2020), Socaciu et al. (2020)

Obolskiy et al. (2011), Szczepanik et al. (2018), Bussmann et al. (2020)

Szczepanik et al. (2018), Sharopov et al. (2020)

Obolskiy et al. (2011)

Szczepanik et al. (2018), Szczepanik et al. (2018)

Osanloo et al. (2017), Socaciu et al. (2020)

Osanloo et al. (2017)

Socaciu et al. (2020)

Osanloo et al. (2017), Szczepanik et al. (2018)

Ayoughi et al. (2011), Obolskiy et al. (2011), Bedini et al. (2017), Osanloo et al. (2017), Sharopov et al. (2020)

Osanloo et al. (2017)

Obolskiy et al. (2011), Behbahani et al. (2017), Szczepanik et al. (2018), Vervandier-Fasseur and Latruffe (2019), Sharopov et al. (2020), Socaciu et al. (2020) Ayoughi et al. (2011), Obolskiy et al. (2011), Joshi et al. (2016), Sharopov et al. (2020) Osanloo et al. (2017), Szczepanik et al. (2018), Bussmann et al. (2020), Sharopov et al. (2020)

(Continued on following page) 
TABLE 1 | (Continued) Chemical composition of $A$. dracunculus essential oil.

Compounds

$\alpha$-Pinene

$\beta$-Pinene

Camphene

p-Cymene

E- $\beta$-Ocymene, Z- $\beta$-ocymene

neo-allo-Ocymene

Thymol

$\beta$-Myrcene

1,8-Cineol, isoterpinolene, artemisinic ketone, isobornyl acetate, pseudolimonene 2-allo-cimene, 2- $\beta$-pinene, endo-isofenchene, trans-carveol, $\alpha$-fenchene $\Delta 3$-carene

Borneol, E-carvone oxide

$\beta$-Sesquifelandrene

Bornyl acetate

Geraniol, p-pinene, trans-ocimene

Myrtenal, pinocarveol

Carvacrol, $\alpha$-terpenyl acetate

Sesquiterpenoids

Spatulenol

\section{Spathunelol}

$\alpha$-Humulene

Germacrene-D-4-ol, $\alpha$-himachalene

Germacrene D

Farnesane

ar-Curcumen, caryophyllene oxide, $\alpha$-bisabolol, $\beta$-bisabolen

E-Caryophyllene

$\beta$-Caryophyllene

Caryophyllene

$\alpha$-Cedrene

Elemene

$E$ - $\beta$-Caryophyllene, $(E, E)$-farnesane, gleenol, $\alpha$-epi-cadinol

bicyclermacren, $\delta$-elemene

$\alpha$-Zingiberene

$E, E-\alpha$-Farnesane

$\alpha$-Bergamotene, acoradiene, germacrene D, cis-trans- $\alpha$-farnesene

$\alpha$-Copaene, $(E)$ - $\beta$-farnesene

$\beta$-Sesquiphellandrene

$\Gamma$-Elemene, ar-curcumene, bicyclogermacrene, $\delta$-cadinene

Diterpenoids

Phytol

Triterpenoids

Squalene

Polyacetylenes

Capillene

1-Phenyl-2,4-hexadiene, 1-phenyl-2,4-hexadiene-1-one

Isocoumarins

3-(1-Z-Butenyl) isocoumarin=(Z)-artemidin, 2-(1-E-butenyl)-isocoumarin $=(E)-$ artemidin

\section{References}

Aglarova et al. (2008), Ayoughi et al. (2011), Obolskiy et al. (2011), Karimi et al (2015), Abdollahnejad et al. (2016), Bedini et al. (2017), Behbahani et al. (2017), Osanloo et al. (2017), Szczepanik et al. (2018), Bussmann et al. (2020), Sharopov et al. (2020)

Aglarova et al. (2008), Ayoughi et al. (2011), Karimi et al. (2015), Behbahani et al. (2017), Osanloo et al. (2017), Szczepanik et al. (2018), Sharopov et al. (2020), Socaciu et al. (2020)

Aglarova et al. (2008), Ayoughi et al. (2011), Obolskiy et al. (2011), Karimi et al. (2015), Bedini et al. (2017), Osanloo et al. (2017), Bussmann et al. (2020), Sharopov et al. (2020)

Ayoughi et al. (2011), Szczepanik et al. (2018), Jahani et al. (2019), Bussmann et al. (2020), Sharopov et al. (2020)

Ayoughi et al. (2011), Obolskiy et al. (2011), Bedini et al. (2017), Behbahani et al. (2017)

Aglarova et al. (2008), Ayoughi et al. (2011)

Aglarova et al. (2008), Ayoughi et al. (2011), Szczepanik et al. (2018)

Aglarova et al. (2008), Ayoughi et al (2011), Behbahani et al. (2017), Osanloo et al. (2017)

Bedini et al. (2017)

Abdollahnejad et al. (2016)

Ayoughi et al. (2011), Abdollahnejad et al. (2016), Bedini et al. (2017), Szczepanik et al. (2018)

Ayoughi et al. (2011)

Karimi et al. (2015)

Ayoughi et al. (2011), Karimi et al. (2015), Behbahani et al. (2017), Osanloo et al. (2017), Sharopov et al. (2020)

Bussmann et al. (2020)

Aglarova et al. (2008)

Aglarova et al. (2008), Szczepanik et al. (2018)

Aglarova et al. (2008), Ayoughi et al. (2011), Obolskiy et al. (2011), Karimi et al. (2015), Abdollahnejad et al. (2016), Bedini et al. (2017), Behbahani et al. (2017), Osanloo et al. (2017), Bussmann et al. (2020)

Osanloo et al. (2017), Szczepanik et al. (2018), Sharopov et al. (2020)

Ayoughi et al. (2011), Karimi et al. (2015), Osanloo et al. (2017), Sharopov et al. (2020)

Obolskiy et al. (2011)

Obolskiy et al. (2011), Karimi et al. (2015)

Bussmann et al. (2020)

Aglarova et al. (2008)

Karimi et al. (2015), Osanloo et al. (2017)

Bedini et al. (2017), Sharopov et al. (2020)

Szczepanik et al. (2018)

Bedini et al. (2017)

Abdollahnejad et al. (2016)

Ayoughi et al. (2011)

Ayoughi et al. (2011), Karimi et al. (2015)

Karimi et al. (2015)

Karimi et al. (2015), Osanloo et al. (2017), Sharopov et al. (2020)

Osanloo et al. (2017)

Osanloo et al. (2017), Sharopov et al. (2020)

Osanloo et al. (2017), Sharopov et al. (2020)

Sharopov et al. (2020)

Ayoughi et al. (2011), Karimi et al. (2015)

Obolskiy et al. (2011)

Aglarova et al. (2008), Chauhan et al. (2010), Verma et al. (2010), Obolskiy et al. (2011), Joshi et al. (2016)

Aglarova et al. (2008)

Aglarova et al. (2008), Sharopov et al. (2020)

(Continued on following page) 
TABLE 1 | (Continued) Chemical composition of $A$. dracunculus essential oil.

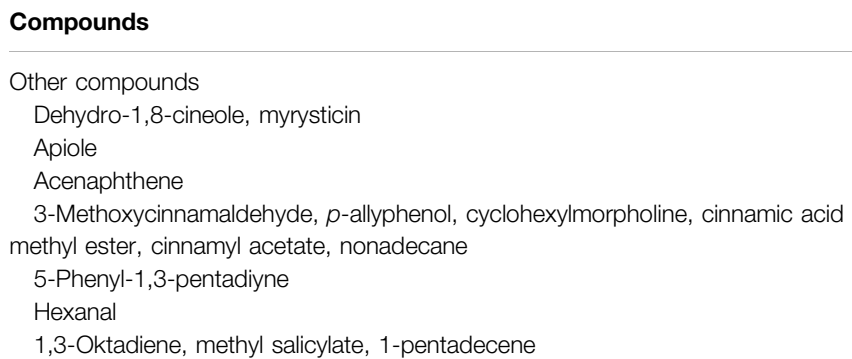

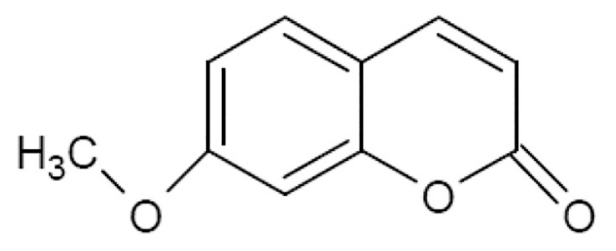

\section{herniarin}

FIGURE 2| Chemical structure of herniarin-compound characteristic for the $A$. dracunculus herb.

with other "green cabbages", or just with salt. As a spice, it restores the appetite, eaten with salad or meat (Syrennivs, 1613).

In Krzysztof Kluk's plant dictionary ("Dykcjonarz roślinny”, 18th c.), the colloquial name "draganek" is given, with the information that it grows in gardens, has lanceolate leaves, tasting "very spicy and pleasant", which strengthen the stomach, "are suitable for salads and seasoning dishes; the vinegar containing these leaves can be very useful on the table" (Kluk, 1805).

In the 18th and 19th centuries, the stimulating tarragon herb was used in Europe as a spice plant rather than a medicinal plant (Reizend, mehr in der Küche als in der Medizin angewendet), which is confirmed by pharmacopoeias and dispensatories of that time: Dispensatorium pharmaceuticum Brunsvicense (Brunsvig 1777), P. J. Bergius, Materia Medica e Regno vegetabili (Stockholm 1782), Pharmacopoea Hispanica (Madrid 1798), Pharmacopoea Wirtemberica (Stuttgart 1798), Codex Medicamentarius sive Pharmacopoea Gallica (Paris 1818), V. L. Brera, Riccettario clinico (Padova 1825). The information given in them is as follows: Artemisia dracunculus L., Kaisersalat, Dragunbeifuß, Dragonkel, Estragon, Serpentine: southern European plant, grown in gardens; use is made of the herb-Herba Dracunculi esculenti sive hortensis-with thin, narrow, lanceolate, green leaves, which have a weak spicy aroma and a sharp, pungent, slightly spicy flavor (Jourdan, 1829).

The 19th-century Real-Encyclopädie der gesamten Pharmazie (1886), apart from providing a morphological description, states that A. dracunculus (Dragun, Bertram) is used as a spice, especially in the form of tarragon vinegar (Acetum Dracunculi) (Vulpius, 1887). The recipe for it can also be

\section{References}

Szczepanik et al. (2018), Sharopov et al. (2020)

Szczepanik et al. (2018)

Joshi et al. (2016), Osanloo et al. (2017)

Osanloo et al. (2017)

Joshi et al. (2016)

Socaciu et al. (2020)

Sharopov et al. (2020) found in the Pharmaceutical Encyclopedia by L. Rządkowski: Acetum Dracunculi-Tarragon vinegar: Herbae Dracunculi recentis concisae 100, Aceti Vini 1000, Ac. Salicylici 1 - digest for eight days, squeeze in a wooden press, heat to a temperature not exceeding $100^{\circ} \mathrm{C}$, filter after a few days. Pour into small bottles, tightly cork, and store lying down (Rządkowski, 1937).

\section{APPLICATIONS IN TRADITIONAL MEDICINE AROUND THE WORLD}

In traditional medicine, $A$. dracunculus is used in ailments of the digestive system, and as an appetite and digestive stimulant, especially when red meat is consumed in large quantities (Uhl and Strauss, 2000). Moreover, the A. dracunculus herb was used to accelerate the metabolism (Senderski, 2007). It was also used as an anesthetic for toothache, wounds and cuts (Mamedov et al., 2004). In Europe the plant's uses also included constipation, intestinal cramps, ulcers and cancer (Obolskiy et al., 2011). In Arabic cultures, the species was used in the treatment of insomnia, gingivitis, foot and mouth disease and as an agent for masking the taste of medicines, while in Central Asia, including Russia, it was used to treat irritation, allergic rashes, gastritis, dyspepsia, dermatitis, and to promote digestion and improve appetite (Mamedov et al., 2004; Sharopov et al., 2020). In Azerbaijan, A. dracunculus was used as an anti-epileptic drug (Alakbarov, 2001). Indian traditional medicine-Ayurveda-relates that the species is effective in the treatment of helminthiasis, intestinal smooth muscle spasms, fever of various origins, and a good tonic, an immunostimulant and to regulates the menstrual cycle (Miller and Miller, 1998; Obolskiy et al., 2011). Native people of Himachal Pradesh and Kashmir use a paste from the leaves of $A$. dracunculus in the treatment of wounds on the legs of yaks and donkeys. Moreover, they use extract of tarragon for toothache, fever, dysentery, intestinal worms and stomach ache (Joshi et al., 2016).

\section{APPLICATIONS IN MODERN PHYTOTHERAPY AND POSITION IN GLOBAL MEDICINE}

A. dracunculus is not a pharmacopeial species. The use of the species in medicine is based only on traditional medicine, but the plant has been a frequent subject of research in many centers 
TABLE 2 | Chemical composition of A. dracunculus.

Group of

compounds

Flavonoids

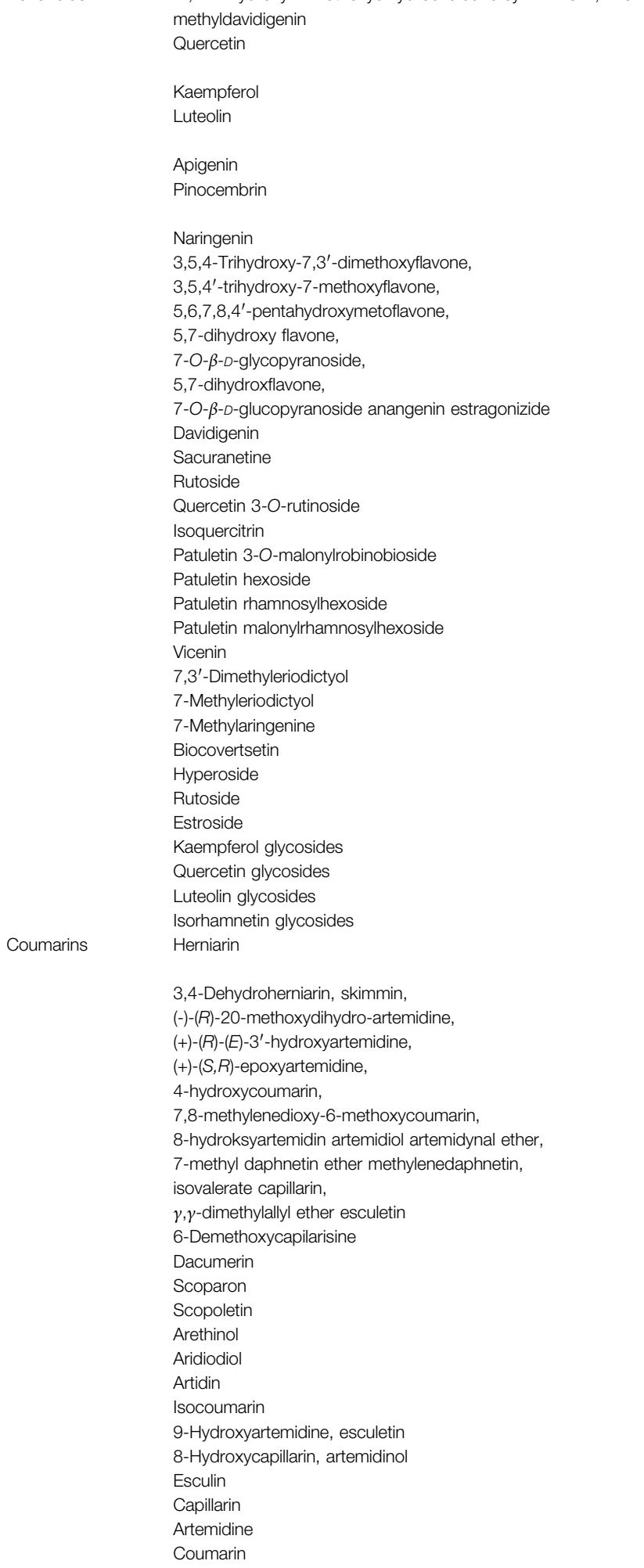

$\begin{array}{lll}\text { Compounds } & \text { References }\end{array}$

Obolskiy et al. (2011), Yu et al. (2019), Majdan et al. (2020)

Obolskiy et al. (2011), Mumivand et al. (2017), Jahani et al. (2019), Bussmann et al. (2020), Majdan et al. (2020)

Obolskiy et al. (2011), Bussmann et al. (2020)

Obolskiy et al. (2011), Mumivand et al. (2017), Jahani et al., 2019, Bussmann et al. (2020)

Mumivand et al. (2017), Majdan et al. (2020)

Obolskiy et al. (2011), Mumivand et al. (2017), Jahani et al., 2019, Bussmann et al. (2020), Majdan et al. (2020)

Obolskiy et al. (2011), Mumivand et al. (2017), Majdan et al. (2020)

Obolskiy et al. (2011)

Obolskiy et al. (2011), Yu et al. (2019), Majdan et al. (2020)

Güvenalp et al. (2017)

Ribeiro et al. (2016)

Majdan et al. (2020)

Bhutia and Valant-vetschera (2008)

Bussmann et al. (2020)

Aglarova et al. (2008)

Aglarova et al. (2008), Majdan et al. (2020)

Aglarova et al. (2008), Güvenalp et al. (2017), Mumivand et al. (2017), Osanloo et al., 2017, Jahani et al., 2019, Aydin et al., 2020, Bussmann et al. (2020)

Aydin et al. (2020)

Obolskiy et al. (2011)

Obolskiy et al. (2011), Majdan et al. (2020)

Bhutia and Valant-vetschera (2008), Obolskiy et al. (2011)

Obolskiy et al. (2011), Bussmann et al. (2020)

Bussmann et al. (2020)

Aglarova et al. (2008)

Aglarova et al. (2008), Obolskiy et al. (2011)

Aglarova et al. (2008), Bhutia and Valant-vetschera, 2008, Obolskiy et al. (2011) Aglarova et al. (2008), Jahani et al. (2019)

(Continued on following page) 
TABLE 2 | (Continued) Chemical composition of $A$. dracunculus.

\begin{tabular}{|c|c|c|}
\hline $\begin{array}{l}\text { Group of } \\
\text { compounds }\end{array}$ & Compounds & References \\
\hline Phenolic acids & $\begin{array}{l}\text { (E) 2-Hydroxy-4-methoxycinnamic acid, } \\
\text { 4,5-di-O-caffeoylquinic acid, } \\
\text { 5-O-caffeoylquinic acid hydroxybenzoic acid, } \\
\text { 3,5-O-dicaffeoylquinic acid, } p \text {-coumaroyl-feruloylquinic acid, } p \text {-coumaroyl- } \\
\text { caffeoylquinic acid, } \\
\text { 4,5-di-O-caffeoylquinic acid, } \\
\text { 5-O-caffeoylquinic acid, } \\
\text { Ferulic acid hexoside } \\
\text { Caffeoylquinic acid, sakuranetin } \\
\text { Chicory acid } \\
\text { Caffeic acid, chlorogenic acid } \\
\text { p-Coumaric acid } \\
\text { Ferulic acid, syringic acid } \\
\text { Vanillic acid } \\
\text { 2-Methoxycinnamic acid }\end{array}$ & $\begin{array}{l}\text { Obolskiy et al. (2011), Ribeiro et al. (2016) } \\
\text { Ribeiro et al. (2016), Majdan et al. (2020) } \\
\text { Majdan et al. (2020) } \\
\text { Obolskiy et al. (2011), Mumivand et al. (2017) } \\
\text { Obolskiy et al. (2011), Mumivand et al. (2017), Jahani et al. (2019), Bussmann et al. } \\
\text { (2020), Majdan et al. (2020) } \\
\text { Mumivand et al. (2017) } \\
\text { Mumivand et al. (2017), Jahani et al. (2019) } \\
\text { Mumivand et al. (2017), Jahani et al., 2019, Bussmann et al. (2020) } \\
\text { Abdollahnejad et al. (2016) }\end{array}$ \\
\hline Alkamides & Neopelitorin A, neopelitorin B, pelitoryin & Obolskiy et al. (2011), Majdan et al. (2020) \\
\hline Sterols & Stigmasterol & Aydin et al. (2020) \\
\hline Fatty acids & Myristic acid, oleic acid, palmitic acid & Obolskiy et al. (2011) \\
\hline Vitamins & Vitamin C & Aglarova et al. (2008), Obolskiy et al. (2011) \\
\hline Minerals & lodine compounds & Mohammadi et al. (2020) \\
\hline Enzymes & Peroxidases & Aglarova et al. (2008) \\
\hline Tannins & No data & Bussmann et al. (2020) \\
\hline \multirow[t]{5}{*}{ Other compounds } & $\begin{array}{l}\text { 1-Methoxy-4-(2-propenyl) benzene, 3,7-dimethyl-1,3,7-octatriene } \\
4-\left(1^{\prime}, 1^{\prime}, 2^{\prime}, 2^{\prime} \text {-Tetramethylpropyl)-1,2-benzenediol }\right. \\
\text { Phytoalexin } \\
\text { Benzyl benzoate, methyl salicylate, trimethoxyallylbenzene } \\
\text { 1,9,2-Octalone, } 7 \text {-methoxy-1-indanone, cinnamic aldehyde, simetyloacetal, } \\
\text { ociminon acetate, 3- methylbenzyl }\end{array}$ & $\begin{array}{l}\text { Obolskiy et al. (2011) } \\
\text { Güvenalp et al. (2017) } \\
\text { Talbi et al. (2016) } \\
\text { Aglarova et al. (2008) } \\
\text { Abdollahnejad et al. (2016) }\end{array}$ \\
\hline & Anisaldehyde & Abdollahnejad et al. (2016), Osanloo et al. (2017) \\
\hline & $\gamma$-Decalactone & Ayoughi et al. (2011), Karimi et al. (2015) \\
\hline & $\begin{array}{l}\text { Cuminic aldehyde, } 2(3 \mathrm{H}) \text {-furanone,5-hexyldihydro-benzen, ethanol, } \\
\text { a-2-propenyl-methyl cinnamate }\end{array}$ & Osanloo et al. (2017) \\
\hline & $\begin{array}{l}(2 E, 4 E) \text {-1-(Piperidin-1-yl)undeca-2,4-diene-8,10-diyn-1-one, }(2 E, 4 E) \text { - } \\
N \text {-isobutyl undeca-2,4-dien-8,10-diynamide }\end{array}$ & $\begin{array}{l}\text { Karimi et al. (2015), Behbahani et al. (2017) } \\
\text { Aydın et al. (2019), Aydin et al. (2020) }\end{array}$ \\
\hline
\end{tabular}

around the world, especially in Iran. New findings on the biological activity of extracts from the herb, leaves, and essential oil of this species-proven by scientific research conducted over the last 10 years-are presented below. The partially known mechanisms of action of A. dracunculus are presented in Table 3.

\section{BIOLOGICAL ACTIVITY CONFIRMED BY SCIENTIFIC RESEARCH}

\section{Antibacterial and Antifungal Activities}

Abdollahnejad et al. conducted a comparative study of the antibacterial potential of $A$. dracunculus herb oil obtained from two different methods: steam distillation and experimentally modified steam distillation. The experiment was carried out using the disk diffusion method and the microdilution method against Staphylococcus aureus, $S$. epidermidis, Micrococcus luteus, Bacillus subtilis, B. cereus, Listeria monocytogenes, Streptococcus pyogenes, $S$. typhimurium, Escherichia coli, Klebsiella pneumoniae, Shigella flexneri, S. marcescens, Pseudomonas aeruginosa and Salmonella spp. All these bacteria were found to be sensitive to the essential oil of $A$. dracunculus, with $S$. epidermidis showing the largest zone of inhibition $(21.5 \mathrm{~mm})$. The MIC value for Gram-positive bacteria did not differ significantly between oils obtained from the different methods, but a significantly lower MIC (minimum inhibitory concentration) value for Gram-negative bacteria was recorded for oil obtained with the modified steam distillation method (Abdollahnejad et al., 2016).

Two years later, a research team from the same facility conducted another experiment confirming the antibacterial activity of A. dracunculus oil against Staphylococcus aureus, Klebsiella spp., Salmonella typhimurium, Staphylococcus epidermidis, Proteus spp. and Corynebacterium diphtheriae. The essential oil was tested with agar well diffusion. A significant inhibitory effect on the growth of $S$. aureus, Proteus spp. and C. diphtheriae bacterial strains was demonstrated. The MIC value for these bacteria was determined using the essential oil at a concentration of 0.03 and $25 \mathrm{mg} / \mathrm{ml}$ (Tajbakhsh and Soleimani, 2018).

Another study evaluating the antibacterial activity of $A$. dracunculus essential oil was conducted in 2020 by Socaciu et al. The experiment was aimed at assessment of the usability 
of the oil in antibacterial edible films. Bacteriostatic and bactericidal activities were evaluated with the Kirby-Bauer disk diffusion test, the minimum inhibitory concentration test (MIC) and the minimal bactericidal concentration (MBC) test. The results of the first test revealed the greatest inhibition of the growth of Salmonella enteritidis than Staphylococcus aureus, Escherichia coli and Listeria monocytogenes. The MIC and $\mathrm{MBC}$ tests displayed the highest bacteriostatic and bactericidal activity against Escherichia coli (5.14 MIC; 5.14 MBC) whereas in Listeria monocytogenes the bactericidal effect was poorer (5.14 MIC; $10.80 \mathrm{MBC}$ ) and lower values of MIC and MBC tests were obtained in Salmonella enteritidis (10.80 MIC; $10.80 \mathrm{MBC}$ ), and Staphylococcus aureus (10.80 MIC; 22.68 MBC) strains (Socaciu et al., 2020).

In 2016, conducted a study evaluating the antibacterial and antifungal activity of hydro-ethanolic extract of $A$. dracunculus. MIC and MBC tests along with the minimum fungicidal concentration test (MFC) were carried out to assess the antimicrobial activity of the extract. The experiment determined significant bactericidal activity of the extract and inhibition of the growth of Staphylococcus aureus, methicillin resistant (MRSA) Bacillus cereus, Micrococcus flavus, Listeria monocytogenes, Pseudomonas aeruginosa, antibiotic resistant (A.R) Pseudomonas eruginosa, Salmonella typhimurium, Escherichia coli, A.R. Escherichia coli and Enterobacter cloacae strains. Bacillus cereus being the most sensitive to the influence of hydro-ethanolic extract of tarragon (0.02 MIC; $0.08 \mathrm{MBC})$ followed by A.R Pseudomonas aeruginosa (0.04 MIC; 0.08 $\mathrm{MBC}$ ) and Enterobacter cloacae (0.04 MIC; $0.08 \mathrm{MBC})$. Moreover, application of the extract in fungal colonies confirmed a notable decrement of the growth of the colonies and the fungicidal effect against Aspergillus fumigatus, Aspergillus versicolor, Aspergillus ochraceus, Aspergillus niger, Trichoderma viride, Penicillum funiculosum, Penicillium ochrochloron, Penicillium verrucosum. The MIC test results didn't differ significantly in different colonies. Interestingly, Aspergillus versicolor and Aspergillus niger had lower responses in the MFC test (0.16) compared with the remaining fungi species (0.08) (Ribeiro et al., 2016).

The effect of hydro-ethanolic extract of $A$. dracunculus leaves on $C$. albicans infection was investigated. The experiment was carried out on an animal model (mouse). The rodents were treated intraperitoneally with the plant extract in doses of 50, $100,200 \mathrm{mg} / \mathrm{kg}$, then they were infected with $0.2 \mathrm{ml}$ of a suspension at a concentration of $10^{5}$ colony-forming units per millilitre (CFU/ml). After sacrificing the animals, the concentration of the pathogen in liver and kidney homogenates was determined. It was found that the growth of C. albicans was significantly inhibited. For the maximum dose of the extract $-200 \mathrm{mg} / \mathrm{kg}$, the concentration of the pathogen in the liver was 16.08 colony-forming units per gram of test material (CFU/g), and no traces of its presence were found in the kidneys. The amount in the control was $36.28 \mathrm{CFU} / \mathrm{g}$ and $53.31 \mathrm{CFU} / \mathrm{g}$, respectively (Zarasvand et al., 2016).

In the other study, used the disk diffusion method, the pourplate method and the dilution method to investigate the antibacterial and antifungal activities of a spice produced from
A. dracunculus against strains of the bacteria: Pseudomonas aeruginosa, Proteus vulgaris, Escherichia coli, Bacillus cereus, $B$. subtilis, Staphylococcus aureus, Streptococcus pyogenes, and the fungi: Aspergillus fumigatus, Penicillium expansum and Candida albicans. At a concentration of $20 \mathrm{mg} / \mathrm{ml}$, a hydro-ethanolic extract from the spice showed antimicrobial activity in the disk diffusion method. The largest zone of growth inhibition was observed for $S$. pyogenes $(18 \mathrm{~mm})$, and the smallest for $P$. aeruginosa $(9 \mathrm{~mm})$. In the pour-plate method, the extract at a concentration of $2 \mathrm{mg} / \mathrm{ml}$ was effective against $S$. pyogenes, $S$. aureus, B. subtilis, B. cereus, C. albicans and A. fumigatus. The extract showed antibacterial activity, but did not completely inhibit the growth of E. coli and P. expansum, and was ineffective against $P$. vulgaris and $P$. aeruginosa. In the microdilution method, the MIC value of the tarragon extract ranged from 2 to $32 \mathrm{mg} / \mathrm{ml}$ (Behbahani et al., 2017).

Majdan et al. investigated the antibacterial effects of aqueous extract of $A$. dracunculus. The study was conducted to evaluate the antibacterial activity of an infusion of aerial parts of tarragon against Gram-positive bacteria: Staphylococcus aureus, $S$. epidermis, Corynebacterium diphtheriae, Enterococcus hirae and Gram-negative bacteria: Klebsiella pneumoniae, Escherichia coli, Proteus vulgaris and Helicobacter pylori colonies. The values of concentrations of the extracts used in the assay ranged from 0.004 to $94.000 \mathrm{mg} / \mathrm{ml}$ (mg-relates to dry extract of $A$. dracunculus and $\mathrm{mL}$ relates to sterile distilled water). The results demonstrated that tarragon infusion was particularly effective against Staphylococcus aureus (MIC $0.09 \mathrm{mg} / \mathrm{ml}$ ), to a lesser extent it also impeded growth of Staphylococcus epidermis (MIC $0.363 \mathrm{mg} / \mathrm{ml}$ ), Corynebacterium diphtheriae (MIC $5.9 \mathrm{mg} /$ $\mathrm{ml}$ ) colonies, Staphylococcus aureus MRSA (MIC $2.35 \mathrm{mg} / \mathrm{ml}$ ) and Helicobacter pylori (MIC $11.75 \mathrm{mg} / \mathrm{ml}$ ) colonies. On the contrary, minimal antimicrobial activity was displayed in Klebsiella pneumoniae (MIC $47 \mathrm{mg} / \mathrm{mL}$ ) and Enterococcus hirae (MIC $23.5 \mathrm{mg} / \mathrm{ml}$ ). Notably, Escherichia coli and Proteus vulgaris strains turned out to be invulnerable to the antimicrobial activity of the infusion (Majdan et al., 2020).

\section{Antiprotozoal Activity}

Iranian researchers have investigated the potential of hydroethanolic extract of $A$. dracunculus in the treatment of leishmaniasis. They tested the effectiveness of various concentrations of the extract $(100-1000 \mu \mathrm{g} / \mathrm{ml})$ by applying them to the promastigote forms of Leishmania major grown in vitro. The recorded MIC values of the extract after 24, 48 and $72 \mathrm{~h}$ were: $962.03,688.36$ and $585.51 \mu \mathrm{g} / \mathrm{ml}$, respectively, which indicates that the plant extract can be used in the treatment of leishmaniasis (Mirzaei et al., 2016).

\section{Antioxidant Effect}

The antioxidant potential of $A$. dracunculus was assessed. For this purpose, fresh tarragon, purchased from the local market, was subjected to extraction with water and ethanol. The extract underwent a DPPH test and was used to determine total amounts of phenols and flavonoids by the spectrophotometric method. The estimated total phenolic content was $24.1 \mathrm{mg} / \mathrm{g}$ dry weight (as gallic acid eq.) and the total flavonoid content was 
TABLE 3 | Pharmacological properties of $A$. dracunculus.

Activity

Anti-bacterial and anti-fungal

Anti-protozoal

Antioxidant

Anti-inflammatory and analgesic

Immuno-modulating

Anti-depressive

Anti-tumor

Hepato-protective

Hypo-glycaemic

Normalizing the profile of thyroid hormones

Inhibiting the activity of carbonic anhydrase I and ||
Mechanism of action

References

Abdollahnejad et al. (2016)

Inhibition of the growth of Staphylococcus aureus, Staphylococcus epidermidis, Micrococcus luteus, Bacillus subtilis, Bacillus cereus, Listeria monocytogenes, Streptococcus pyogenes, Streptococcus typhimurium, Escherichia coli, Klebsiella pneumoniae, Shigella flexneri, Shigella marcescens, Pseudomonas aeruginosa and Salmonella sp. under the influence of the essential oil of the $A$. dracunculus herb

Staphylococcus aureus, Proteus spp. and Corynebacterium diphtheriae colony growth inhibition after application of the essential oil essential oil of $A$. dracunculus leaves hampers the growth of Escherichia coli, Listeria monocytogenes, Salmonella enteritidis and Staphylococcus aureus strains

Staphylococcus aureus, Staphylococcus aureus MRSA (methicillin resistant), Bacillus cereus, Micrococcus flavus, Listeria monocytogenes, Pseudomonas eruginosa, A.R Pseudomonas eruginosa, Salmonella typhimurium, Escherichia coli, A.R Escherichia coli, Enterobacter cloacae colonies growth inhibition and bactericidal effect as well as inhibition of the growth of Aspergillus fumigatus, Aspergillus versicolor, Aspergillus ochraceus, Aspergillus niger, Trichoderma viride, Penicillum funiculosum, Penicillium ochrochloron, Penicillium verrucosum and fungicidal activity under the influence of hydro-ethanolic extract of tarragon hydro-ethanolic extract of $A$. dracunculus leaves significantly reduces the number of colony-forming units (CFU) of Candida albicans in the liver and kidneys of mice Inhibition of the growth of bacteria: Pseudomonas aeruginosa, Proteus vulgaris, Escherichia coli, Bacillus cereus, Bacillus subtilis, Staphylococcus aureus, Streptococcus pyogenes, and fungi: Aspergillus fumigatus, Penicillium expansum and Candida albicans, under the influence of hydro-ethanolic herbal extract

Inhibition of the growth of bacteria: Staphylococcus aureus, Staphylococcus epidermis, Staphylococcus aureus MRSA, Corynebacterium diphtheriae and Helicobacter pylori after the application of infusion of $A$. dracunculus and minimal inhibition effect in Enterococcus hirae, Klebsiella pneumoniae colonies Inhibition of the development of the promastigote form of Leishmania major

Reducing properties of the hydro-ethanolic herbal extract related to the presence of phenolic compounds and flavonoids

Reduction of DPPH and ABTS in the presence of phenolic compounds

Reduction of pain sensations and reduction of xylene-induced ear edema after administration of the ethanolic herbal extract to mice

Inhibition of ROS, IL-8 and TNF- $\alpha$ production in imitated inflammation

Reduction in IL-17 and IFN- $\gamma$ production and intensification of the phagocytosis process carried out by macrophages

Lowering of IL-17 and IL-23 levels and reduces the infiltration of leukocytes into brain cells

Increased neutrophil levels and decreased lymphocyte levels after intraperitoneal administration of the hydro-ethanolic extract from the leaves

Increased resistance to stressful situations and reduction of stress-related levels of inflammatory cytokines

The phenolic compounds and flavonoids contained in the A. dracunculus herb reduce the immobility response time in mice in the writhing test and in the forced swim test

Mild inhibition of hMAO-A and hMAO-B by extracts of $A$. dracunculus

Inhibition of proliferation of mouse lymphoma cells (L5178YD) due to the presence of polyphenols and alkamides in leaf extracts

Decrease in levels of alanine transaminase, aspartate transaminase, alkaline phosphatase and total bilirubin, and increase in total protein levels Decrease in glycated hemoglobin, decrease in area under curve for insulin, decrease in total insulin secretion, decrease in systolic blood pressure, and increase in HDL-C

Increase in thyroxine and triiodothyronine levels, decrease in elevated levels of thyrotropin, and increase in total antioxidant capacity, increase in glutathione, and decrease in malondialdehyde levels

Compounds contained in herbal extracts reduce the activity of carbonic anhydrase I and II.
Tajbakhsh and Soleimani (2018)

Socaciu et al. (2020)

Ribeiro et al. (2016)

Zarasvand et al. (2016)

Behbahani et al. (2017)

Majdan et al. (2020)

Mirzaei et al. (2016)

Behbahani et al. (2017), Ribeiro et al. (2016),

Mumivand et al. (2017)

Zarezade et al. (2018)

Eidi et al. (2016)

Majdan et al. (2020)

Abtahi Froushani et al. (2016)

Safari et al. (2019)

Modaresi et al. (2018)

Wang et al. (2018)

Jahani et al. (2019)

Aydin et al. (2020)

Navarro-Salcedo et al. (2017)

Zarezade et al. (2018)

Méndez-Del Villar et al. (2016)

Mohammadi et al. (2020)

Aydın et al. (2019)

(Continued on following page) 
TABLE 3 | (Continued) Pharmacological properties of $A$. dracunculus.

\begin{tabular}{ll}
\hline Activity & \multicolumn{1}{c}{ Mechanism of action } \\
\hline Repelling insects & $\begin{array}{l}\text { Inhibition of Calliphora vomitoria egg laying on fresh beef, on which the essential Bedini et al. (2017) } \\
\text { oil of } A \text {. dracunculus herb was applied } \\
\text { Larvacidal effect against Anopheles stephensi under the influence of } \\
\text { nanoemulsion of } A \text {. dracunculus essential oil }\end{array}$
\end{tabular}

$20 \mathrm{mg} / \mathrm{g}$ dry weight (as quercetin eq.). In the DPPH test, the $\mathrm{IC}_{50}$ value was $65.5 \mu \mathrm{g} / \mathrm{ml}$, which confirms that $A$. dracunculus extracts can produce antioxidant effects (Behbahani et al., 2017).

The antioxidant activity has also been confirmed by other study where performed DPPH and ABTS tests and assessed the total phenolic content, thus verifying the activity of the hydroethanolic extract from the $A$. dracunculus herb. The total amount of phenols, expressed as gallic acid equivalents, was $197.22 \mathrm{mg} / \mathrm{g}$ dry weight. High activity of the extract was also demonstrated in the DPPH and ABTS tests (Zarezade et al., 2018).

The antioxidant activity of hydro-ethanolic extract of tarragon was also evaluated. First, Ribeiro et al. analyzed the phenolic content of the extract with HPLC. The results showed $147.5 \mathrm{mg}$ of the phenolic content in $1 \mathrm{~g}$ of the dried product including approximately $31.9 \mathrm{mg} / \mathrm{g}$ of flavonoids and $115.6 \mathrm{mg} / \mathrm{g}$ of phenolic acids. Then the team used different methods of assessing the antioxidant activity: the DPPH test examining radical scavenging activity, the $\beta$-carotene/linoleate test, reducing power was measured by the capacity to convert $\mathrm{Fe}^{3+}$ to $\mathrm{Fe}^{2+}$ and the TBARS assay evaluating the level of lipid peroxidation. Ribeiro et al. used ascorbic acid as a positive control. The results displayed that the extract is most effective as a reducing agent (Ribeiro et al., 2016).

In 2017, the researches from Iran and USA together also carried out DPPH tests, in addition to the ferric reducing antioxidant power (FRAP) test. For the experiment, hydromethanolic extracts were used, which were prepared from the herb of A. dracunculus collected from various parts of Iran. The results showed that the antioxidant potential depended on the region from which the harvested plants originated. It was positively correlated with the concentration of compounds with phenolic and flavonoid structures. The highest reducing capacity was proven for extracts from the A. dracunculus herb collected in Birjand (a city in eastern Iran) - in the DPPH test the $\mathrm{IC}_{50}$ value was $0.039 \mathrm{mg} / \mathrm{ml}$; in the FRAP test the extract was reduced $148.29 \mu \mathrm{mol} \mathrm{Fe}{ }^{2+} / \mathrm{g}$ dry weight. The total amount of phenols calculated as gallic acid equivalents was $96.52 \mathrm{mg} / \mathrm{g}$ dry weight, and the total amount of flavonoids calculated as rutoside equivalents was $50.4 \mathrm{mg} / \mathrm{g}$ dry weight (Mumivand et al., 2017).

\section{Anti-inflammatory and Analgesic Effects}

The Iranian research centers have investigated the antinociceptive and anti-inflammatory potential of an ethanolic extract from the A. dracunculus herb. The potential analgesic effect was verified in an animal model (mouse) using the hot plate test, the writhing test and the formalin test. Anti-inflammatory activity was assessed in a xylene-induced ear edema model. The study group received intraperitoneally the herbal ethanolic extract in doses of 5, 10, 50 , or $100 \mathrm{mg} / \mathrm{kg} \mathrm{BW}$ (body weight), while the control group was intraperitoneally administered a saline solution. Reduction in pain sensation was observed in all three tests. In the hot plate test, the extract administered in doses of 50 and $100 \mathrm{mg} / \mathrm{kg}$ increased the pain threshold after one hour. Interaction with opioid receptors may be responsible for the analgesic effect of the plant extract, as administration of naloxone to the animals reduced the antinociceptive effect of the extract. Anti-inflammatory activity has also been confirmed a significant reduction in ear edema was demonstrated with the extract administered in doses of 50 and $100 \mathrm{mg} / \mathrm{kg}$ (Eidi et al., 2016).

A study carried out by Majdan et al. mentioned above, evaluated the anti-inflammatory activity of aqueous extract of A. dracunculus. In the experiment researchers used neutrophils derived from venous peripheral blood from healthy human donors. Thereafter, to assess the secretion of cytokines after the incitement of neutrophils, an enzyme-linked immunosorbent assay (ELISA) was used. The application of aqueous extract of tarragon produced a decrement of the release of IL- 8 (by 4.0 and 4.8\%) and TNFa (by 7.8 and $5.2 \%)$. Moreover, ROS production was also measured. It was evaluated by microplate reader which displayed an inhibition of ROS production by $1.4 \%$ (Majdan et al., 2020).

\section{Immunomodulatory Action}

An experiment was conducted on laboratory animals (mice) to evaluate the immunomodulatory properties of an aqueous extract of A. dracunculus herb. The mice were immunized intraperitoneally with sheep erythrocytes then orally administered an aqueous extract of the A. dracunculus herb. An increase in the level of antibodies to sheep erythrocytes and a decrease in cellular immunity were documented. The treatment was also shown to reduce the production of pro-inflammatory agents-IL-17 and IFN- $\gamma$, and to increase the phagocytic potential of macrophages. The authors of the study concluded that an aqueous extract of the $A$. dracunculus herb could be a good immunomodulating agent; moreover, it was free from potentially harmful estragole and methyl eugenol (Abtahi Froushani et al., 2016).

The studies on the potential use of aqueous extract of $A$. dracunculus in the treatment of multiple sclerosis were performed, too. The experiments were carried out on mice in which autoimmune encephalomyelitis (EAE) was induced with the myelin oligodendrocyte glycoprotein. This model is an experimental animal model for multiple sclerosis. It has been proven that giving rodents aqueous extract of $A$. dracunculus 
significantly alleviates the symptoms of the disease. By using the iron (III) reduction method, an increase in the antioxidant potential was verified. The use of the extract also reduced the level of inflammatory cytokines (IL-17 and IL-23) and the infiltration of leukocytes into brain cells. The results of the study indicate that the compounds contained in $A$. dracunculus can potentially be used in the treatment of multiple sclerosis (Safari et al., 2019).

Studies of Modaresi et al. determined the effect of hydroethanolic extract from A. dracunculus leaves on the hematological parameters of mice. The parameters assessed were levels of leukocytes, erythrocytes, lymphocytes, monocytes and neutrophils. It was demonstrated that intraperitoneal administration of the extract at a dose of $200 \mathrm{mg} / \mathrm{kg}$ significantly increased the level of neutrophils in the blood of rodents and reduced lymphocyte levels. There were no significant effects on the number of leukocytes, red blood cells or monocytes (Modaresi et al., 2018).

\section{Antidepressant Effect}

Ethanolic extract of $A$. dracunculus was tested for its potential to increase mental resilience. The study was conducted on mice administered orally with extract of A. dracunculus shoots. A model of depression with repetitive stress caused by fear of social failure was tested by leaving the rodents in a cage with an aggressive individual for $10 \mathrm{~min}$ and checking their tendency to avoid contact. The treatment was shown to increase resistance to depression and to reduce the level of inflammatory cytokines associated with the presence of stress (Wang et al., 2018).

An experiment conducted in 2019 has confirmed the antidepressant activity of the species. Harvested herb of $A$. dracunculus was subjected to extraction with ethanol, then the activity of the extract was assessed on animals (NMRI mice and Swiss mice), by performing the forced swim test, the writhing test, and the open-field test. The results of the study showed a reduction in immobility time in the forced swim test (for the extract dose of $400 \mathrm{mg} / \mathrm{kg}$ the immobility time was $153.6 \mathrm{~s}$, and was shorter compared to the control group, in which the immobility time was $202.3 \mathrm{~s}$ ), a reduction in immobility time in the writhing test (for the extract dose of $200 \mathrm{mg} / \mathrm{kg}$ the period of immobility was $117.2 \mathrm{~s}$, and was shorter compared to the control group, in which the immobility time was $142.6 \mathrm{~s}$ ). In the open-field test, the rodents' mobility did not change significantly, except for the trial with Swiss mice, which were administered $100 \mathrm{mg} / \mathrm{kg}$ of $A$. dracunculus herb extract.

The authors of the study associate the plant's antidepressant activity with the presence of phenolic and flavonoid compounds, such as chlorogenic acid, caffeic acid or luteolin and quercetin (Jahani et al., 2019).

In 2020 scientists from Turkey carried out an experiment evaluating the influence of $A$. dracunculus extracts on human monoamine oxidase A (hMAO-A) and monoamine oxidase- $\mathrm{B}$ (hMAO-B). Isoenzymes are an important factor in the development of neurodegenerative diseases such as Alzheimer's disease and Parkinson's disease as well as in depression. Inhibitors of the enzymes have displayed efficiency in the treatment of neurodegenerative diseases and they are being used in treatment of clinical depression and anxiety. The teams prepared extracts of tarragon with different solvents: ethyl acetate, acetone, methanol and water to compare the activity of various types of extracts. Moreover, pure metabolites herniarin and skimmin were also tested to verify their influence on the isoenzymes. The results determined a nonselective and lower inhibitory activity of tarragon extracts and pure metabolites on hMAO-A and hMAO-B in comparison with reference inhibitors (Selegiline and Clorgyline). The most effective of the extracts proved to be the methanol extract. Interestingly, pure metabolites had lower inhibitory activity on hMAO-A and hMAO-B compared with extracts. In this regard, the researchers suggested that there are synergistic interactions between compounds of the extract (Aydin et al., 2020).

\section{Anti-Tumor Effect}

Researchers from Mexico have assessed the effect of $A$. dracunculus leaf extract on the proliferation of mouse lymphoma L5178Y cells. Extraction of the plant material was performed with hexane, ethyl acetate, acetone, ethanol, acetonitrile and supercritical carbon dioxide $\left(\mathrm{scCO}_{2}\right)$. Antitumor activity was assessed using a tumor growth inhibition test that included measuring ascitic fluid volume and the number of tumor cells after administration of the plant extract to mice. In the control group the tumor cell count was $17.969 \times 10^{6}$, whereas in the group of mice receiving the acetonitrile extract from $A$. dracunculus leaves the cell count was $0.1 \times 10^{6}$. Oral administration of the extract obtained with supercritical carbon dioxide reduced the number of cells to $12.9 \times 10^{6}$, whereas intraperitoneal administration of the same extract reduced the number of cells to $0.1 \times 10^{6}$. The anti-tumour activity of the acetonitrile extract is likely related to the high concentration of polyphenols, and the effect of the $\mathrm{scCO}_{2}$ extract is attributed to the presence of a higher concentration of alkamides in it (Navarro-Salcedo et al., 2017).

\section{Hepatoprotective Action}

The hepatoprotective activity of a hydro-alcoholic extract of the herb of A. dracunculus was confirmed in 2018 as part of the cooperation between three research centers in Iran. In the course of the experiment, rats were given 50,100 , or $200 \mathrm{mg} / \mathrm{kg}$ of the extract for 15 days, followed by a single dose of carbon tetrachloride. Evidence was documented of a reduction in the levels of alanine transaminase, aspartate transaminase, alkaline phosphatase and total bilirubin, as well as a total protein increase. Histopathological examination also confirmed less liver damage in the group of animals given the herbal hydro-alcoholic extract (Zarezade et al., 2018).

\section{Hypoglycaemic Action}

The effect of ethanolic extract of $A$. dracunculus herb on controlling glycaemia, insulin sensitivity and insulin secretion was tested. For this purpose, a randomized, double-blind clinical trial was conducted in 24 patients diagnosed with impaired glucose tolerance. Twice daily, the encapsulated ethanolic extract of $A$. dracunculus was administered at $1000 \mathrm{mg}$ for 90 days. The documented results show a significant decrease in 
systolic blood pressure $(120 \mathrm{~mm} \mathrm{Hg}$ in the control group, $113 \mathrm{mmHg}$ in the test group), a decrease in glycosylated hemoglobin concentration $(5.8 \%$ in the control group, $5.6 \%$ in the test group), a decrease in the area under the curve for insulin levels (56.136-27.426 pmol/L in the control group, 44.472 to $23.370 \mathrm{pmol} / \mathrm{L}$ in the test group), and a reduction in the insulinogenic index $(0.45-0.23$ in the control group, 0.35 to 0.18 in the test group). HDL cholesterol levels increased. The results of the study showed that $A$. dracunculus herb extracts may in future be used as a therapeutic agent in the treatment of impaired glucose tolerance (Méndez-Del Villar et al., 2016).

\section{Thyroid Hormone Profile Regulation}

The study assessed whether the A. dracunculus herb could be used in hypothyroidism. It was conducted on a group of forty-eight rats in which hypothyroidism was induced by the administration of propylthiouracil. The rodents were orally administered an aqueous extract of the herb. Samples of the animals' blood were taken during the experiment. A significant increase in the level of thyroxine and triiodothyronine was proven after the administration of $300 \mathrm{mg} / \mathrm{kg}$ of the plant extract; moreover, a decrease in the elevated level of thyrotropin was recorded in the negative control group. At a dose of $200 \mathrm{mg} / \mathrm{kg}$, the extract increased the total antioxidant capacity (TAC) and the level of glutathione. There was also a decrease in the level of malonaldehyde, a marker of oxidative stress. The research results indicate that $A$. dracunculus aqueous extract may improve the thyroid hormone profile, but further research is needed (Mohammadi et al., 2020).

\section{Inhibition of Carbonic Anhydrase I and II Activity}

The study verified whether A. dracunculus herb extracts obtained with n-hexane, dichloromethane, ethanol and methanol are inhibitors of carbonic anhydrase I and II (hCA I and hCA II). In the body, these enzymes catalyze the reaction between water and carbon dioxide, which produces a proton and a bicarbonate anion. This reaction has a significant impact on the water content inside the eyeball. With excess fluid buildup, intraocular pressure rises, which can lead to the development of glaucoma. In the study, the highest activity $\left(\mathrm{IC}_{50}=0.02 \mu \mathrm{g} / \mathrm{ml}\right.$ for hCA I, and $\mathrm{IC}_{50}=0.31 \mu \mathrm{g} / \mathrm{ml}$ for hCA II $)$ was demonstrated for the dichloromethane extract. In order to determine the active compounds responsible for the action, the following main components were isolated from the dichloromethane extract: trans-anethole, stigmasterol, herniarin (2E, 4E)-N-isobutylundeca-2,4-diene-8,10-diynamide (2E, 4E)-1-(piperidin-1-yl)undeca-2,4-diene-8,10-diyn-1-one and 1-(4'-methoxyphenyl)-1,2,3-trihydroxypropane. All these compounds inhibited the activity of hCA I and hCA II. The action of 1-( $4^{\prime}$-methoxyphenyl)-1,2,3-trihydroxypropane was more potent than that of the control acetazolamide. On the basis of their research, the authors of the study concluded that A. dracunculus herb extracts, like anhydrase I and II inhibitors, can reduce the accumulation of fluid inside the eyeball and thus be used in the treatment of glaucoma (Aydin et al., 2019).

\section{Insect-Repelling Action}

Italian researchers have verified that the essential oil obtained from the herb A. dracunculus can act as a repellent against a species of dipterous flies-Calliphora vomitoria (the blue bottle fly). The insect, which is a synanthropic species, is responsible for the transmission of many pathogenic microorganisms-Salmonella typhimurium, Entamoeba coli, and Giardia duodenalis. Larvae that hatch from its eggs deposited on animal or human tissue cause myiasis. The essential oil of the plant has been shown to deter C. vomitoria from laying eggs in fresh beef. At an oil concentration of $0.05 \mu \mathrm{L} / \mathrm{cm}^{2}$, complete inhibition of egg laying by the insect was demonstrated (Bedini et al., 2017).

Osanloo et al. (2017) conducted a study confirming larvicidal activity of tarragon essential oil against Anopheles stephensi-mosquitos that are responsible for spreading malaria in the Arabian Peninsula, Indian subcontinent, Afghanistan and Iran. Chemical larvicides which are widely used to control the disease cause environmental pollution and desensitization of some species to active agents. Therefore, nanoemulsion of $A$. dracunculus essential oil was tested as a natural alternative to chemical products. The results showed that nanoemulsion consisting of $0.35 \%$ tarragon oil, $10 \%$ of Tween 20 and deionized water has a comparable larvicidal activity to chemical larvicides (Osanloo et al., 2017).

\section{APPLICATIONS IN COSMETOLOGY}

The European CosIng database allows the use of A. dracunculus in six forms (European Commission CosIng, 2020). The species is used in the cosmetics industry as an ingredient in skin care products, fragrances and masking agents. In cosmetology, $A$. dracunculus is used in the production of moisturizing creams, shampoos, lotions and cleansing milk. These preparations are used to care for the skin of the scalp, body and face (Table 4). The essential oil obtained by steam distillation is widely used as a component in perfumes (Aglarova et al., 2008). It is also used in aromatherapy during massages and baths and is added to facial masks and compresses (Hassanzadeh et al., 2016; Mumivand et al., 2017). Products containing tarragon are offered by both European and non-European cosmetics companies. Among them are brands such as the English Lush Cosmetics, the Italian L'Erbolario Assenzio, the German AER Scent, the French Florame, the Swedish Timotei, the Azerbaijani Buta and the South Korean Missha. As a component of women's and men's perfumes, the oil of $A$. dracunculus is very often used by prestigious fashion brands, such as the Italian Prada, Versace, Dolce \& Gabbana, the French Givenchy and Chloé, the American Calvin Klein and Tom Ford, and many others.

\section{APPLICATIONS IN THE FOOD INDUSTRY}

The US Food and Drug Administration (FDA) states that the composition of the spice tarragon includes dried leaves and flowering tops of A. dracunculus (Food and Drug 
Administration, 1980). Tarragon is usually used as a seasoning for meat, sauces, rice dishes, fish and marinades. It has preservative properties, so it is keenly used for pickling cabbage and cucumbers, marinating pumpkins, and for the production of tarragon mustard and herbal vinegars. It is recommended for people on a salt-free diet because it improves the taste of dishes (Kordali et al., 2005; MéndezDel Villar et al., 2016; Çorapc1 et al., 2020). It is also added to infusions, refreshing drinks, alcoholic and non-alcoholic drinks such as "Tarkhun" - a carbonated, non-alcoholic drink, the main ingredient of which are fresh $A$. dracunculus leaves. Fresh tarragon leaves can be used as side dishes or garnishes with meat dishes and in vegetable salads (Goldstein, 1999; Ribnicky et al., 2004; Aglarova et al., 2008).

The nutritional composition of tarragon comprises a high content of carbohydrates $(88 \mathrm{~g} / 100 \mathrm{~g}$ dried weight), lower amounts of fructose and sucrose as well as low levels of fat with a predominance of polyunsaturated fatty acids (Ribeiro et al., 2016). Use of the species in the food industry varies from country to country. Tarragon is a important herb in French cuisine. French tarragon or estragon comes from there and is the most popular variety of the spice for use in cooking. French tarragon has a refreshing, sweet and slightly bitter fragrance. The ground parts are used whole, both fresh and dried. After drying, it is milled or crushed. However, the fresh herb is more desirable, as dried herbs quickly lose their qualities. In France, tarragon is one of the key plants used in the production of Dijon mustard, cream sauces and mayonnaize. Armenians use tarragon to season vegetables, fish and meats. In Slovenia, tarragon is used to season the pastry called 'potica'. In the United States, it is added to vinegar, tartar sauce and seafood (Goldstein, 1999; Ribnicky et al., 2004; Aglarova et al., 2008; Çorapc1 et al., 2020).

The taste of $A$. dracunculus depends on the variety. French tarragon has a sweet taste and aroma similar to liquorice, with a slightly bitter aftertaste. Another description of French tarragon says that it has a herbaceous flavor similar to anise and basil. Russian tarragon is more bitter and pungent, devoid of the anise flavor (Uhl and Strauss, 2000).

Professional studies suggest that hydro-ethanolic extract of $A$. dracunculus, with its antimicrobial activity, can be considered a potential candidate for application in food as a preservative. Additionally, hydro-ethanolic extract is less toxic compared to essential oils, therefore, it has the potential to be used in the food industry. Furthermore, tarragon extract also displayed improvement in the fracture of pizza dough as well as a lower influence on dough darkening compared with ascorbic acid (Gottardi et al., 2016; Ribeiro et al., 2016).

A notable potential application of $A$. dracunculus essential oil is in edible antibacterial films used to prevention food spoilage. In 2020 a study by Socaciu and co-authors confirmed the antibacterial and antioxidant activity of tarragon oil. Moreover, the experiment also evaluated the influence of the oil on the qualities of edible antibacterial film. The results show that the application of essential oil in the film forming solution improved water solubility, protection against VIS light, puncture resistance, elasticity and transparency of the film and an increased of its moisture content. Therefore, tarragon oil can be considered an alternative to synthetic compounds in food packaging applications (Socaciu et al., 2020).

\section{SAFETY OF USE}

The FDA lists A. dracunculus and the oils and extracts derived from this species as safe for use (Food and Drug Administration, 2020). However, there have been reports of potential toxicity of the main components of the essential oil of the plant-estragole and methyl eugenol (Obolskiy et al., 2011). Methyl eugenol and estragole, as components of A. dracunculus, have both undergone extensive safety checks. Tests on animals administered estragole orally or subcutaneously have shown induction of liver tumors in mice. The appearance of tumors is associated with the formation of $1^{\prime}$-hydroxyestragole. This metabolite was also present in the urine of men who were given $100 \mu \mathrm{g}$ of estragole for six months. Both compounds (estragole and 1'-hydroxyestragole) promoted abnormal DNA synthesis in rat hepatocytes, in both in vivo and in vitro tests (European Commission Health and Comsumer Protection Directorate - General, 2001).

Methyl eugenol has also been found to induce liver tumors in animal studies (rats and mice) and, additionally, the formation of neuroendocrine tumors in the glandular stomach. Neoplasms of the kidney, mammary glands and subcutaneous tissue, and mesotheliomas have also been documented in rats. High doses of methyl eugenol (minimum $30 \mathrm{mg} / \mathrm{kg}$ for 25 days) induce auto-induction of P450 cytochromes, leading to the formation of the carcinogenic $1^{\prime}$-hydroxymethyl eugenol. As in the case of estragole, methyl eugenol and its metabolites promote unplanned DNA synthesis; moreover, methyl eugenol forms DNA adducts (European Commission Health and Comsumer Protection Directorate-General, 2001).

After analyzing the available data, the European Food Safety Authority (EFSA) classified estragole and methyl eugenol as genotoxic and carcinogenic compounds. However, a safe threshold for their consumption has not been established. The Commission recommends limiting the use of both compounds (European Commission Health and Comsumer Protection Directorate - General, 2001).

The data of European Medicines Agency - The Committee on Herbal Medicinal Products (HMPC) from 2019 regarding the estragole use claimed that "there is the evidence of genotoxic carcinogenicity, exposure to this compound; estragole should be kept as low as practically achievable. In the evaluation of herbal medicinal products containing estragole Member States should take steps to ensure that the public are protected from exposure." HMPC recommended the acceptable intake of estragole per day for adults - $51.8 \mathrm{mg} / \mathrm{kg}$ of body weight, and for children $1.0 \mu \mathrm{g} / \mathrm{kg}$ of body weight. Moreover, report concluded, that the intake of estragole from (traditional) herbal medicinal products in the population should be as low as possible (European Medicines Agency - The Committee on Herbal Medicinal Products (HMPC), 2019). 
TABLE 4 | Applications of $A$. dracunculus in cosmetology as recommended by the Coslng database.

Name according to CosIng

Artemisia dracunculus flower

Artemisia dracunculus herb extract

Artemisia dracunculus leaf/stem extract

Artemisia dracunculus oil

Artemisia dracunculus root extract

Artemisia dracunculus seed/Anthemis nobilis seed/Hypericum

androsaemum seed extract

\section{Description}

Flowers of the tarragon plant

Extract from tarragon herb

Extract from tarragon leaves and stems

Essential oil of tarragon

Extract from tarragon roots

Extract from tarragon seeds, roman chamomile seeds,

and tutsan (shrubby st. John's wort) seeds

\section{Application profile}

Skin care agent

Fragrance

Masking agent

Fragrance, skin care agent

Skin care agent

Skin care agent

\section{PLANT BIOTECHNOLOGY RESEARCH}

Due to the extensive use of tarragon in the food industry, large losses incurred with the traditional methods of its cultivation, difficulties in vegetative reproduction, and diseases of the cultivated plants, research is being conducted on alternative, biotechnological methods of propagating A. dracunculus.

In 2012, scientists developed an efficient protocol for micropropagation of the French variety of $A$. dracunculus. Plant cuttings $20 \mathrm{~mm}$ long were cut into $1 \mathrm{~mm}$ long pieces. These were then used to establish cultures in Murashige \& Skoog (MS) liquid media, with five apical meristems as the experimental unit. In order to propagate the plant material, the established cultures were transferred to solid MS media. The tested propagation protocols differed from one another in the concentrations of indole acetic acid (IAA) and kinetin (KIN) added to the medium. The MS medium enriched with only $0.1 \mathrm{mg} / \mathrm{L}$ each of IAA and KIN, proved to be the most effective. The length of the sprouts was $11.19 \mathrm{~mm}$ and the multiplication index was 1.97. Thirteen days after planting, $100 \%$ rooting was achieved. As an alternative method of propagation, the authors of the study placed the propagating pieces horizontally on a solid MS medium supplemented with $0.5 \mathrm{mg} / \mathrm{L}$ KIN and $0.5 \mathrm{mg} / \mathrm{L}$ IAA. The sprout length was $10.31 \mathrm{~mm}$ and the multiplication index was 1.87; good callus induction and leaf development were also demonstrated. The time required to establish the in vitro culture was three weeks (Fernández-Lizarazo and Mosquera-Vásquez, 2012).

Türközü et al. also undertook to develop an A. dracunculus micro-propagation protocol. They proved that the highest efficiency $(92 \%)$ could be obtained by growing cultures in MS medium supplemented with $1.8 \mu \mathrm{M}$ 6-benzyladenine (BA) and $0.3 \mu \mathrm{M}$ 1-naphthylacetic acid (NAA). They also reported an adverse effect of the addition of gibberellic acid $\left(\mathrm{GA}_{3}\right)$ on microshoot development. The longest roots were obtained in the plants grown on MS medium with the addition of indolelbutyric acid (IBA) at a concentration of $0.5 \mathrm{mg} / \mathrm{L}$ $(44 \mathrm{~mm})$ and on $1 / 2$ MS medium with $0.5 \mathrm{mg} / \mathrm{L} \mathrm{IBA}(46 \mathrm{~mm})$ (Türközü et al., 2014).

Another team of Ibrahim et al. has tested the performance of various explants-leaves, stems and roots of $A$. dracunculus in establishing in vitro cultures. Leaf explants placed on MS medium supplemented with $1.0 \mathrm{mg} / \mathrm{ml}$ of 2,4dichlorophenoxyacetic acid (2,4-D) proved to be the best starting material for callus induction. For root and stem explants, no statistically significant effects were obtained. It was also proved that the best callus induction was caused by the addition of $0.5 \mathrm{mg} / \mathrm{L} \mathrm{BA}$ and $0.1 \mathrm{mg} / \mathrm{L} \mathrm{NAA}$ (75 shoots). It was also shown that the concentration of estragole in the cultured plants correlated with the type of explant and the phytohormone concentrations used. Estragole was not detected in the roots; the highest amount of it (16.7\% estragole per g dry weight) was isolated from one-node cultures after the application of $0.5 \mathrm{mg} / \mathrm{L}$ 2,4-D (Ibrahim et al., 2011).

\section{SUMMARY}

A. dracunculus has been a frequent subject of research in the last few years, regarding both the chemistry and biological activity of extracts obtained from the herb and/or leaves, and the essential oil. Phytochemical tests have confirmed the presence of numerous flavonoid compounds, phenolic acids, coumarins and alkamides in the herb and leaves, as well as a very high variability of the chemical composition of the essential oil. Contemporary research on the biological activity of the above-mentioned raw materials has proven new findings in their activity-antibacterial, antifungal and antiprotozoal effects, as well as extremely valuable antioxidant, immunomodulatory and antineoplastic properties. These studies have also proven hepatoprotective, hypoglycaemic and thyroidregulating effects. An antidepressant effect has also been documented. The anti-inflammatory and analgesic effects known from traditional medicine applications have also been confirmed.

The popularity of $A$. dracunculus in the production of cosmetics is also surprising. For this purpose, the essential oil of tarragon, extracts from the flowers, leaves, stems and seeds, as well as from the whole herb and roots are used. The essential oil is also used in aromatherapy treatments and in the production of perfumes. Cosmetics based on this species are offered by both European cosmetics companies (mainly English, German, French, Swedish) and non-European companies (mainly South Korean and Azerbaijani). The herb of the species is widely used for seasoning purposes and as an additive to alcoholic and non-alcoholic beverages. The species is the subject of research in the field of plant biotechnology, which mainly concerns the development of micropropagation protocols. The most valuable findings in the professional scientific research conducted has been the proof of new areas of the biological activity of the A. dracunculus herb and/or leaf extracts and essential oil-mainly their antioxidant, 
immunomodulating and antineoplastic effects, as well as the hepatoprotective and hypoglycaemic effects. The species, known thus far as a spice plant, appears to be an extremely valuable medicinal and cosmetic plant.

\section{AUTHOR CONTRIBUTIONS}

Data collection: HE, JŚ, EK, PK, AR, AS; design of the study: HE; analysis and interpretation of the data: HE, EK, JS, PK, AR, AS,

\section{REFERENCES}

Abdollahnejad, F., Kobarfard, F., Kamalinejad, M., Mehrgan, H., and Babaeian, M. (2016). Yield, chemical composition and antibacterial activity of Artemisia dracunculus L. essential oils obtained by two different methods. J. Essent. Oil Bearing Plants 19 (3), 574-581. doi:10.1080/0972060X.2014.963167

Abtahi Froushani, S. M., Zarei, L., Esmaeili Gouvarchin Ghaleh, H., and Mansori Motlagh, B. (2016). Estragole and methyl-eugenol-free extract of Artemisia dracunculus possesses immunomodulatory effects. Avicenna J. Phytomedicine 6 (5), 526-534. doi:10.22038/ajp.2016.6479

Aglarova, A. M., Zilfikarov, I. N., and Severtseva, O. V. (2008). Biological characteristics and useful properties of tarragon (Artemisia dracunculus L.) (review). Pharm. Chem. J. 42 (2), 81-86. doi:10.1007/s11094-008-0064-3

Alakbarov, F. U. (2001). Medicinal plants used in medieval Azerbaijan phytotherapy. J. Herbal Pharmacother. 1 (3), 35-49. doi:10.1080/ j157v01n03_04

Aydin, T., Akincioglu, H., Gumustas, M., Gulcin, I., Kazaz, C., and Cakir, A. (2020). Human monoamine oxidase (hMAO) A and hMAO B inhibitors from Artemisia dracunculus L. herniarin and skimmin. Z. Naturforsch. - Sect. C J. Biosci. 75 (11-12), 459-466. doi:10.1515/znc-2019-0227

Aydın, T., Yurtvermez, B., Șentürk, M., Kazaz, C., and Çakır, A. (2019). Inhibitory effects of metabolites isolated from Artemisia dracunculus L. against the human carbonic anhydrase I (hCA I) and II (hCA II). Rec. Nat. Prod. 13 (3), 216-225. doi:10.25135/rnp.102.18.07.329

Ayoughi, F., Barzegar, M., Sahari, M. A., and Naghdibadi, H. (2011). Chemical compositions of essential oils of Artemisia dracunculus L. and endemic Matricaria chamomilla $\mathrm{L}$. and an evaluation of their antioxidative effects. J. Agric. Sci. Technol. 13, 79-88.

Bakova, N., Logvinenko, L., and Shevchuk, O. (2017). Tarragon cultivars (Artemisia dracunculus L.) of the Nikita botanical gardens breeding. $B$. Proc., 1, 445-451.

Bauhin, J., and Cherler, J. H. (1651). Historia plantarum universalis. Vol III Ebroduni. Available at: https://books.google.pl/books/about/Historia_ plantarum_universalis.html?id=7ejDuAEACAAJ\&redir_esc $=y \quad$ (Accessed November 1, 2020).

Bedini, S., Flamini, G., Cosci, F., Ascrizzi, R., Echeverria, M. C., Guidi, L., et al. (2017). Artemisia spp. essential oils against the disease-carrying blowfly Calliphora vomitoria. Parasites Vectors 10 (1), 1-10. doi:10.1186/s13071017-2006-y

Behbahani, B. A., Shahidi, F., Yazdi, F. T., Mortazavi, S. A., and Mohebbi, M. (2017). Antioxidant activity and antimicrobial effect of tarragon (Artemisia dracunculus) extract and chemical composition of its essential oil. Food Measure 11 (2), 847-863. doi:10.1007/s11694-016-9456-3

Bhutia, T. D., and Valant-Vetschera, K. M. (2008). Chemodiversity of Artemisia dracunculus $\mathrm{L}$. from Kyrgyzstan: isocoumarins, coumarins, and flavonoids from aerial parts. Nat. Prod. Commun. 3 (8), 1289-1292. doi:10.1177/ $1934578 \times 0800300811$

Bora, K. S., and Sharma, A. (2011). The GenusArtemisia: a comprehensive review. Pharm. Biol. 49 (1), 101-109. doi:10.3109/13880209.2010.497815

Bussmann, R. W., Batsatsashvili, K., Kikvidze, Z., Khajoei Nasab, F., Ghorbani, A., Paniagua-Zambrana, N. Y., et al. (2020). "Artemisia absinthium L., Artemisia annua L., Artemisia dracunculus L., Artemisia leucodes Schrenk, Artemisia
MT. Drafting the manuscript: HE, PK, AR, AS; critical revision of the manuscript: HE, AS, MT. All authors read and approved the manuscript in its final form.

\section{FUNDING}

This research was funded by grand numbers: N42/DBS/000010 and N42/DBS/000136 supported by the Polish Ministry of Science and Higher Education.

scoparia Waldst. and Kit. Artemisia vulgaris L., Eclipta prostrata (L.) L," in Asteraceae in Ethnobotany of the mountain Regions of far eastern Europe. Editors K. Batsatsashvili, Z. Kikvidze, and R. Bussmann (Cham, Switzerland: Springer), 131-146. doi:10.1007/978-3-030-28940-9_16

Catalogue of Life (2020). Catalogue of Life. Available at: http://www. catalogueoflife.org/ (Accessed November 8, 2020).

Chaleshtori, R. S., Rokni, N., Razavilar, V., and Kopaei, M. R. (2013). The evaluation of the antibacterial and antioxidant activity of tarragon (Artemisia dracunculus L.) essential oil and its chemical composition. Jundishapur J. Microbiol. 6 (9), 1-35. Available at: https://www.scopus.com/ inward/record.uri?eid=2-s2.0-84889675506\&doi=10.5812\%2Fjjm.7877\&partnerID= 40\&md5=8db9e949587e1022af0488d25336b422 (Accessed November 7, 2020).

Chauhan, R. S., Kitchlu, S., Ram, G., Kaul, M. K., and Tava, A. (2010). Chemical composition of capillene chemotype of Artemisia dracunculus L. from NorthWest Himalaya, India. Ind. Crops Prod. 31 (3), 546-549. doi:10.1016/j.indcrop. 2010.02.005

Çorapcı, B., Köstekli, B., Eyüboğlu, A., and Kocatepe, D. (2020). The effect of different application methods of sumac (Rhus coriaria) and tarragon (Artemisia dracunculus) on some quality properties of marinated sea bream (Sparus aurata L., 1758). J. Food Process. Preserv. 44 (10), e14751. doi:10.1111/jfpp.14751

Długońska, H. (2015). The Nobel Prize 2015 in physiology or medicine for highly effective antiparasitic drugs. Ann. Parasitol. 61 (4), 299-301. doi:10.17420/ ap6104.23

Efferth, T., Zacchino, S., Georgiev, M. I., Liu, L., Wagner, H., and Panossian, A. (2015). Nobel Prize for artemisinin brings phytotherapy into the spotlight. Phytopharm. 22 (13), 1-4. doi:10.1016/j.phymed.2015.10.003

Eidi, A., Oryan, S., Zaringhalam, J., and Rad, M. (2016). Antinociceptive and antiinflammatory effects of the aerial parts of Artemisia dracunculus in mice. Pharm. Biol. 54 (3), 549-554. doi:10.3109/13880209.2015.1056312

Eisenman, S. W., Poulev, A., Struwe, L., Raskin, I., and Ribnicky, D. M. (2011) Qualitative variation of anti-diabetic compounds in different tarragon (Artemisia dracunculus L.) cytotypes. Fitoterapia 82 (7), 1062-1074. doi:10. 1016/j.fitote.2011.07.003

European Commission Cosing (2020). CosIng - cosmetic database. Available at: https://ec.europa.eu/growth/sectors/cosmetics/cosing_en (Accessed November $10,2020)$.

European Commission Health \& Comsumer Protection Directorate - General (2001). Opinion of the scientific committee on food on estragole (1-allyl-4methoxybenzene). Int. J. Mod. Phys. Conf. Ser. doi:10.1142/s2010194512007544

European Medicines Agency - The Committee on Herbal Medicinal Products (HMPC) (2019). Public statement on the use of herbal medicinal products containing estragole. Available at: https://www.ema.europa.eu/en/documents/ other/second-draft-revision-1-public-statement-use-herbal-medicinal-productscontaining-estragole_en.pdf (Accessed November 10, 2020).

Fernández-Lizarazo, J. C., and Mosquera-Vásquez, T. (2012). Efficient micropropagation of French tarragon (Artemisia dracunculus L.). Agron. Colomb Available at: http://www.scielo.org.co/scielo.php?pid=S012099652012000300004\&script=sci_arttext\&tlng=en (Accessed November 8, 2020).

Food and Drug Administration (2020). CPG sec 525.750 spices - definitions FDA. Available at: https://www.fda.gov/regulatory-information/search-fda-guidancedocuments/cpg-sec-525750-spices-definitions (Accessed November 8, 2020).

Food and Drug Administration (1980). Spices - definitions. Available at: https:// www.fda.gov/regulatory-information/search-fda-guidance-documents/cpgsec-525750-spices-definitions. 
GBIF.org (2020). GBIF Home Page. Available at: https://www.gbif.org/ (Accessed November 18, 2020).

Goldstein, D. (1999). The Georgian feast: the vibrant culture and savory food of the Republic of Georgia. Los Angeles, CA: University of California Press.

Gottardi, D., Bukvicki, D., Prasad, S., and Tyagi, A. K. (2016). Beneficial effects of spices in food preservation and safety. Front. Microbiol. 7, 1394. doi:10.3389/ fmicb.2016.01394

Güvenalp, Z., Özbek, H., Dursunoğlu, B., Yuca, H., Gözcü, S., Çil, Y. M., et al. (2017). $\alpha$-Amylase and $\alpha$-glucosidase inhibitory activities of the herbs of Artemisia dracunculus $L$. and its active constituents. Med. Chem. Res. 26 (12), 3209-3215. doi:10.1007/s00044-017-2014-7

Hassanzadeh, M. K., Tayarani Najaran, Z., Nasery, M., and Emami, S. A. (2016). Tarragon (Artemisia dracunculus L.) oils. Essent. Oils Food Preserv., Flavor Saf. 813-817. doi:10.1016/B978-0-12-416641-7.00092-4

Ibrahim, A. K., Ahmed, S. A., Khattab, S. E., and Sherif, F. M. E. (2011). Efficient callus induction, plant regeneration and estragole estimation in tarragon (Artemisia dracunculus L.). J. Essent. Oil Res. 23 (4), 16-20. doi:10.1080/ 10412905.2011.9700463

Jahani, R., Khaledyan, D., Jahani, A., Jamshidi, E., Kamalinejad, M., Khoramjouy, M., et al. (2019). Evaluation and comparison of the antidepressant-like activity of Artemisia dracunculus and Stachys lavandulifolia ethanolic extracts: an in vivo study. Res. Pharm. Sci. 14 (6), 544-553. doi:10.4103/1735-5362.272563

Joshi, R., Satyal, P., and Setzer, W. (2016). Himalayan aromatic medicinal plants: a review of their ethnopharmacology, volatile phytochemistry, and biological activities. Medicines 3 (1), 6. doi:10.3390/medicines3010006

Jourdan, A. J. L. (1829). Pharmacopoea universalis: oder, Uebersicht der Pharmacopöen von Amsterdam Erster Band, Weimar Available at: https://books.google.pl/books/ about/Pharmacopoea_universalis.html?id=eB0SAAAAYAAJ\&redir_esc=y (Accessed November 2, 2020).

Karimi, A., Hadian, J., Farzaneh, M., and Khadivi-Khub, A. (2015). Phenotypic diversity and volatile composition of Iranian Artemisia dracunculus. Ind. Crops Prod. 65, 315-323. doi:10.1016/j.indcrop.2014.12.003

Kluk, K. (1805). Dykcyonarz roślinny. Warszawa, Poland: Meiy Rzeczypospolitej. Available at: https://polona.pl/item/dykcyonarz-roslinny-w-ktorym-podlugukladu-linneusza-sa-opisane-rosliny-nietylko-kraiowe,MzM2NTk3Mw/2/\#info: metadata (Accessed November 5, 2020).

Kordali, S., Kotan, R., Mavi, A., Cakir, A., Ala, A., and Yildirim, A. (2005). Determination of the chemical composition and antioxidant activity of the essential oil of Artemisia dracunculus and of the antifungal and antibacterial activities of Turkish Artemisia absinthium, A. dracunculus, Artemisia santonicum, and Artemisia spicigera Essential oils. J. Agric. Food Chem. 53 (24), 9452-9458. doi:10. 1021/jf0516538

Koul, B., and Taak, P. (2017). The Artemisia genus: a review on traditional uses, phytochemical constituents, pharmacological properties and germplasm conservation. J. Glycomics Lipidomics 07 (1), 142. doi:10.4172/2153-0637. 1000142

Majdan, M., Kiss, A. K., Hałasa, R., Granica, S., Osińska, E., and Czerwińska, M. E. (2020). Inhibition of neutrophil functions and antibacterial effects of tarragon (Artemisia dracunculus L.) infusion-phytochemical characterization. Front. Pharmacol. 11, 947. doi:10.3389/fphar.2020.00947

Mamedov, N., Grdner, Z., and Craker, L. E. (2004). Medicinal plants used in Central Asia for the treatment of selected skin conditions. J. Herbs Spices Med. Plants 11, 191-222.

Mattioli, P. (1586). Kreuterbuch: des hochgelehrten weitberuİmbten Herrn Petri Andreae Matthioli GruÎndtliche ErklaÎrung Aller Kreutter vnd gewechs mit Eigentlicher Beschreibung derselbigen, in sech $\tilde{A} \ddot{Y}$ erley. Frankfurt Main, Germany: Feyerabend Fischer \& Dack.

Méndez-del Villar, M., Puebla-Pérez, A. M., Sánchez-Peña, M. J., González-Ortiz, L. J., Martínez-Abundis, E., and González-Ortiz, M. (2016). Effect of Artemisia dracunculus administration on glycemic control, insulin sensitivity, and insulin secretion in patients with impaired glucose tolerance. J. Med. Food 19 (5), 481-485. doi:10.1089/jmf.2016.0005

Miller, L., and Miller, B. (1998). Ayurveda and aromatheraphy: the earth essential guide to ancient wisdom and modern healing. New Dehli, India: Motilal Banarsidass Publisher.

Mirzaei, F., Bafghi, A. F., Mohaghegh, M. A., Jaliani, H. Z., Faridnia, R., and Kalani, H. (2016). In vitro anti-leishmanial activity of Satureja hortensis and Artemisia dracunculus extracts on Leishmania major promastigotes. J. Parasit. Dis. 40 (4), 1571-1574. doi:10.1007/s12639-015-0730-9

Missouri Botanical Garden (2020). Tropicos.org. Available at https://www. missouribotanicalgarden.org/ (Accessed November 15, 2020).

Modaresi, M., Alasvand Zarasvand, M., and Madani, M. (2018). The effects of hydroalcoholic extract of Artemisia dracunculus L. (Tarragon) on hematological parameters in mice. Jbrms 5 (1), 10-14. doi:10.29252/jbrms.5.1.10

Mohammadi, M. M., Saeb, M., and Nazifi, S. (2020). Experimental hypothyroidism in adult male rats: the effects of Artemisia dracunculus aqueous extract on serum thyroid hormones, lipid profile, leptin, adiponectin, and antioxidant factors. Comp. Clin. Pathol. 29 (2), 485-494. doi:10.1007/s00580-019-03080-0

Mumivand, H., Babalar, M., Tabrizi, L., Craker, L. E., Shokrpour, M., and Hadian, J. (2017). Antioxidant properties and principal phenolic phytochemicals of Iranian tarragon (Artemisia dracunculus L.) accessions. Hortic. Environ. Biotechnol. 58 (4), 414-422. doi:10.1007/s13580-017-0121-5

Navarro-Salcedo, M. H., Delgado-Saucedo, J. I., Siordia-Sánchez, V. H., GonzálezOrtiz, L. J., Castillo-Herrera, G. A., and Puebla-Pérez, A. M. (2017). Artemisia dracunculus extracts obtained by organic solvents and supercritical $\mathrm{CO} 2$ produce cytotoxic and antitumor effects in mice with L5178Y lymphoma. J. Med. Food 20 (11), 1076-1082. doi:10.1089/jmf.2017.0044

Obistioiu, D., Cristina, R. T., Schmerold, I., Chizzola, R., Stolze, K., Nichita, I., et al. (2014). Chemical characterization by GC-MS and in vitro activity against Candida albicans of volatile fractions prepared from Artemisia dracunculus, Artemisia abrotanum, Artemisia absinthium and Artemisia vulgaris. Chem. Cent. J. 8 (1), 6. doi:10.1186/1752-153X-8-6

Obolskiy, D., Pischel, I., Feistel, B., Glotov, N., and Heinrich, M. (2011). Artemisia dracunculus L. (tarragon): a critical review of its traditional use, chemical composition, pharmacology, and safety. J. Agric. Food Chem. 59 (21), 11367-11384. doi:10.1021/jf202277w

Osanloo, M., Amani, A., Sereshti, H., Abai, M. R., Esmaeili, F., and Sedaghat, M. M. (2017). Preparation and optimization nanoemulsion of Tarragon (Artemisia dracunculus) essential oil as effective herbal larvicide against Anopheles stephensi. Ind. Crops Prod. 109, 214-219. doi:10.1016/j.indcrop.2017.08.037

Pedanius, D. (1998). Der wiener Dioskurides: Codex medicus graecus 1. Editor O. Mazal. (Graz: Akademische Druck u. Verlagsanstalt).

Plinii Secundii, C. (1845). Historiae naturalis libri XXXVIIJ. Łukaszewicz Poznań: Drukarnia Lukasiewicza. Available at: https://polona.pl/item/k-pliniuszastarszego-historyi-naturalnej-ksiag-xxxvii-c-plinii-secundi-historiae,MTc1MjM2/ 2/\#info:metadata (Accessed November 2, 2020).

Rejewski, M. (1996). Pochodzenie łacińskich nazw roślin polskich: przewodnik botaniczny. Warszawa, Poland: Książka i Wiedza.

Ribeiro, A., Barros, L., Calhelha, R. C., Carocho, M., Ćirić, A., Sokovic, M., et al. (2016). Tarragon phenolic extract as a functional ingredient for pizza dough: comparative performance with ascorbic acid (E300). J. Funct. Foods 26, 268-278. doi:10.1016/j.jff.2016.08.019

Ribnicky, D. M., Poulev, A., O’Neal, J., Wnorowski, G., Malek, D. E., Jäger, R., et al. (2004). Toxicological evaluation of the ethanolic extract of Artemisia dracunculus $\mathrm{L}$. for use as a dietary supplement and in functional foods. Food Chem. Toxicol. 42 (4), 585-598. doi:10.1016/j.fct.2003.11.002

Rządkowski, L. (1937). Encyklopedia farmaceutyczna. Poznań: Wydawnictwo Encyklopedii Farmaceutycznej Leon, Mikołaj Wawrzyniec Misiak i S-ka.

Safari, H., Anani Sarab, G., and Naseri, M. (2019). Artemisia dracunculus L. modulates the immune system in a multiple sclerosis mouse model. Nutr. Neurosci. 1, 1-7. doi:10.1080/1028415X.2019.1681742

Senderski, M. E. (2007). Prawie wszystko o ziołach. Poradnik. Mateusz E. Senderski. Podkowa Leśna.

Sharopov, F. S., Salimov, A., Numonov, S., Bakri, M., Sangov, Z., Habasi, M., et al. (2020). Chemical compositions and biological activities of essential oils-original article phytochemical study on the essential oils of tarragon (Artemisia dracunculus L.) growing in Tajikistan and its comparison with the essential oil of the species in the rest. Nat. Prod. Comm. 15, 1-7. doi:10.1177/ 1934578X20977394

Socaciu, M.-I., Fogarasi, M., Semeniuc, C. A., Socaci, S. A., Rotar, M. A., Mureşan, V., et al. (2020). Formulation and characterization of antimicrobial edible films based on whey protein isolate and tarragon essential oil. Polymers 12 (8), 1748. doi:10.3390/POLYM12081748 
Syrennivs, S. (1613). Zielnik Herbarzem z języka łacinskiego zowiq̨. Kraków: Drukarnia Bazylego Skalskiego.

Szczepanik, M., Walczak, M., Zawitowska, B., Michalska-Sionkowska, M., Szumny, A., Wawrzeńczyk, C., et al. (2018). Chemical composition, antimicrobial activity and insecticidal activity against the lesser mealworm Alphitobius diaperinus (Panzer) (Coleoptera: Tenebrionidae) of Origanum vulgare $\mathrm{L}$. ssp. hirtum (Link) and Artemisia dracunculus L. essential oils. J. Sci. Food Agric. 98 (2), 767-774. doi:10.1002/jsfa.8524

Tajbakhsh, M., and Soleimani, N. (2018). Evaluation of the bactericidal effects of Zingiber officinale, Aloysia citrodora and Artemisia dracunculus on the survival of standard gram-positive and gram-negative bacterial strains. Jorjani Biomed. J. 6 (1), 22-32. doi:10.29252/jorjanibiomedj.6.1.22

Tak, I.-U.-R., Mohiuddin, D., Ganai, B. A., Chishti, M. Z., Ahmad, F., and Dar, J. S. (2014). Phytochemical studies on the extract and essential oils of Artemisia dracunculus L. (Tarragon). Afr. J. Plant Sci. 8 (1), 72-75. doi:10.5897/AJPS2013. 1145

Talbi, M., Saadali, B., Boriky, D., Bennani, L., Elkouali, M. h., and Ainane, T. (2016). Two natural compounds - a benzofuran and a phenylpropane - from Artemisia dracunculus. J. Asian Nat. Prod. Res. 18 (8), 724-729. doi:10.1080/ 10286020.2016 .1158708

Tan, R. X., Zheng, W. F., and Tang, H. Q. (1998). Biologically active substances from the genus Artemisia. Planta Med. 64 (4), 295-302. doi:10.1055/s-2006957438

The Plant List (2013). The plant list. Available at: http://www.theplantlist.org/ (Accessed November 8, 2020).

Türközü, D., Yaşar, F., Ellİaltıoğlu, ş. ş., and Yıldırım, B. (2014). Researches on in vitro propagation of tarragon (Artemisia dracunculus L.). Yüzüncü Yil Üniversitesi J. Agric. Sci.

Uhl, S. R., and Strauss, S. (2000). Handbook of spices, seasonings and flavorings. Lancaster, United Kingdom: Technomic Publishing.

Verma, M. K., Anand, R., Chisti, A. M., Kitchlu, S., Chandra, S., Shawl, A. S., et al. (2010). Essential oil composition of Artemisia dracunculus L. (Tarragon) growing in Kashmir -India. J. Essent. Oil Bearing Plants 13 (3), 331-335. doi:10.1080/0972060X.2010.10643830

Vervandier-Fasseur, D., and Latruffe, N. (2019). The potential use of resveratrol for cancer prevention. Molecules 24 (24), 4506. doi:10.3390/molecules 24244506

Vulpius, D. (1887). Real-Encyclopädie der gesammten Pharmacie. Handwörterbuch für Apotheker, Aerzte und Medicinalbeamte, herausgegeben von Prof Dr. Geissler und Prof. Dr. Möller. Verlag von Urban und Schwarzenberg. Wien und Leipzig. 1887. Archiv der Pharmazie. 225 (23), 1075-1077. doi:10.1002/ardp.18872252312

Wang, J., Fernández, A. E., Tiano, S., Huang, J., Floyd, E., Poulev, A., et al. (2018). An extract of Artemisia dracunculus L. promotes psychological resilience in a mouse model of depression. Oxidative Med. Cell Longevity 2018, 1. doi:10.1155/2018/7418681

Watson, B., and Kennel, E. (2014). The Herb Society of America-Artemesia spp. Available at: https://www.herbsociety.org/file_download/inline/d52eae8cbe89-497d-94b3-7fc8da4105f1 (Accessed November 1, 2020).

Willcox, M. (2009). Artemisia Species: from traditional medicines to modern antimalarials-and back again. J. Altern. Complement. Med. 15, 101-109. doi:10. 1089/act.2009.1530910.1089/acm.2008.0327

Yamada, M., Nakamura, K., Watabe, T., Ohno, O., Kawagoshi, M., Maru, N., et al. (2011). Melanin biosynthesis inhibitors from Tarragon-Artemisia dracunculus. Biosci. Biotechnol. Biochem. 75 (8), 1628-1630. doi:10.1271/bbb.110306

Yu, Y., Simmler, C., Kuhn, P., Poulev, A., Raskin, I., Ribnicky, D., et al. (2019). The designer approach helps decipher the hypoglycemic bioactive principles of Artemisia dracunculus (Russian tarragon). J. Nat. Prod. 82 (12), 3321-3329. doi:10.1021/acs.jnatprod.9b00548

Zarasvand, M. A., Madani, M., and Modaresi, M. (2016). The effect of hydroalcoholic extract of Artemisia dracunculus L. (Tarragon) on Candida albicans infection in mice. Jundishapur J. Nat. Pharm. Prod. 11 (4), 2-5. doi:10.17795/jinpp-29911

Zarezade, V., Moludi, J., Mostafazadeh, M., Mohammadi, M., and Veisi, A. (2018). Antioxidant and hepatoprotective effects of Artemisia dracunculus against $\mathrm{CCl}_{4}$-induced hepatotoxicity in rats. Avicenna J. Phytomedicine 8 (1), 51-62. doi:10.22038/ajp.2017.19137.1738

Conflict of Interest: The authors declare that the research was conducted in the absence of any commercial or financial relationships that could be construed as a potential conflict of interest.

Copyright (๐) 2021 Ekiert, Światkowska, Knut, Klin, Rzepiela, Tomczyk and Szopa. This is an open-access article distributed under the terms of the Creative Commons Attribution License (CC BY). The use, distribution or reproduction in other forums is permitted, provided the original author(s) and the copyright owner(s) are credited and that the original publication in this journal is cited, in accordance with accepted academic practice. No use, distribution or reproduction is permitted which does not comply with these terms. 